\title{
Impact of a medicane on the oceanic surface layer from a coupled, kilometre-scale simulation
}

\author{
Marie-Noëlle Bouin ${ }^{1,2}$ and Cindy Lebeaupin Brossier ${ }^{1}$ \\ ${ }^{1}$ CNRM, Université de Toulouse, Météo-France, CNRS, Toulouse, France \\ ${ }^{2}$ Univ. Brest, CNRS, IRD, Ifremer, Laboratoire d'Océanographie Physique et Spatiale (LOPS), IUEM, \\ 29840 Brest, France
}

Correspondence: Marie-Noëlle Bouin (marie-noelle.bouin@meteo.fr)

Received: 24 April 2020 - Discussion started: 30 April 2020

Revised: 10 July 2020 - Accepted: 13 August 2020 - Published: 23 September 2020

\begin{abstract}
A kilometre-scale coupled ocean-atmosphere numerical simulation is used to study the impact of the 7 November 2014 medicane on the oceanic upper layer. The processes at play are elucidated through analyses of the tendency terms for temperature and salinity in the oceanic mixed layer. While comparable by its maximum wind speed to a Category 1 tropical cyclone, the medicane results in a substantially weaker cooling. As in weak to moderate tropical cyclones, the dominant contribution to the surface cooling is the surface heat fluxes with secondary effects from the turbulent mixing and lateral advection. Upper-layer salinity decreases due to heavy precipitation that overcompensates the salinizing effect of evaporation and turbulent mixing. The upper-layer evolution is marked by several features believed to be typical of Mediterranean cyclones. First, strong, convective rain occurring at the beginning of the event builds a marked salinity barrier layer. As a consequence, the action of surface forcing is favoured and the turbulent mixing dampened with a net increase in the surface cooling as a result. Second, due to colder surface temperature and weaker stratification, a cyclonic eddy is marked by a weaker cooling opposite to what is usually observed in tropical cyclones. Third, the strong dynamics of the Strait of Sicily enhance the role of the lateral advection in the cooling and warming processes of the mixed layer.
\end{abstract}

\section{Introduction}

Tropical cyclones (TCs) have been known for long to result in a strong cooling of the oceanic upper layer. In situ measurements from ship (Leipper, 1967) then using buoy arrays (Cione et al., 2000; D'Asaro, 2003) and more recently satellite observations (e.g. Lin et al., 2005; Chiang et al., 2011) showed that they generate a cold wake with maximum amplitude in their right-rear quadrant (in the Northern Hemisphere) which can lower the sea surface temperature (SST) by 5 to $6^{\circ} \mathrm{C}$. This surface cooling can have a strong feedback effect on the cyclone development and intensity as SST controls for a large part the surface enthalpy flux (e.g. Bender et al., 1993; Schade and Emanuel, 1999). This typical ocean response (and feedbacks) has motivated many studies documenting the processes at play and the factors controlling its amplitude.

The oceanic processes at the origin of the cooling have been investigated in case studies involving simulations (Price, 1981; Morey et al., 2006; Huang et al., 2009; Chen et al., 2010) or based on observations (Sanford et al., 1987; D'Asaro, 2003; D'Asaro et al., 2007; Vincent et al., 2012a). Turbulence injected into the oceanic mixed layer (OML) by the surface wind stress results in a very strong vertical shear at the base of the OML with respect to the underlying thermocline. For cyclones with a translation speed above $\sim 1-$ $2 \mathrm{~m} \mathrm{~s}^{-1}$, near-inertial currents act to reinforce this shear and establish a vertical oscillation with a period slightly below the inertial period and amplitude of 20 to $40 \mathrm{~m}$ (Greatbatch, 1983; Shay, 2010). The first upwelling of this series of alternate vertical motions contributes to cool the upper layer by bringing colder water from below the thermocline into the 
OML. The resulting change in the mixed-layer depth (MLD) can further alter the OML budget and its response to the atmospheric forcing. This turbulent mixing usually accounts for most of the cooling effect in strong cyclones (Category 2 or above in the Saffir-Simpson scale). A global study based on the simulation of more than 3000 TCs evaluated its contribution to $56 \%$ of the SST cooling on average within $200 \mathrm{~km}$ of the TC track. This contribution varies depending on the TC intensity from $\sim 30 \%$ of the total cooling for the weakest cyclones to more than $90 \%$ for the most intense ones (Vincent et al., 2012a). Surface heat fluxes also act to cool the upperocean layer mainly through the latent heat flux. They account for the remaining part of the surface cooling, which is up to $70 \%$ for the weakest TCs but less then $10 \%$ for the TCs of intensity 4 or above. Lateral advection also contributes as a secondary process, accounting for nearly $10 \%$ of the total cooling for the strongest TCs and a larger proportion for weaker ones. It may especially reinforce the asymmetry of the cold wake originating from the shear-driven turbulence at the base of the OML (e.g. Price, 1981; Huang et al., 2009; Vincent et al., 2012a).

Cyclone intensity and translation speed are key criteria controlling the cooling magnitude and its spatial extent. More intense cyclones generate stronger cooling, and slowmoving cyclones produce stronger cooling for a given intensity (Lloyd and Vecchi, 2011; Mei and Pasquero, 2013). Slow-moving cyclones also produce cold wakes of a larger extent and more symmetrical because the upwelling has more time to settle (Vincent et al., 2012a).

The amplitude and spatial extent of the cold wake also depend on the ocean preconditioning with a strong influence of the pre-storm SST, upper-layer stratification, and MLD. The amplitude of the cooling has been shown to vary by 1 order of magnitude depending on the ocean state prior to the cyclone passage (Vincent et al., 2012b). In strong TCs, a shallower MLD or stronger stratification favour more intense cooling as the turbulent mixing at the base of the OML more efficiently brings colder water upwards (Schade and Emanuel, 1999). Colder SSTs or lower ocean heat content (generally defined as the temperature integral from the surface down to the $26^{\circ} \mathrm{C}$ isotherm depth; Leipper and Volgenau, 1972) result in weaker TCs and associated weaker cooling.

Upper-layer oceanic features like fronts or eddies also have the potential to modulate the upper-ocean response to a TC. Statistical studies based on 30 to 3000 cases showed that both anticyclonic and cyclonic eddies can influence the TC development through the upper-ocean feedback (Lin et al., 2008; Jullien et al., 2014). Anticyclonic eddies deepen the OML and limit the SST cooling by insulating the warm surface layer against storm-induced upwelling and mixing. Conversely, cyclonic eddies are associated with shallower OML and lead to stronger surface cooling.

The surface cooling can also be altered by salinity stratification. Salinity-induced barrier layers (BLs; Godfrey and Lindstrom, 1989) form in the presence of less saline water at the surface due to rain freshening, run-off, or horizontal advection. They uncouple the OML, driven by salinity, from the isothermal surface layer and form an intermediate barrier layer (at least $5 \mathrm{~m}$ deep) that is more saline than the OML and warmer than the water below the thermocline. Two recent studies based on climatological datasets (Yan et al., 2017) and idealized coupled simulations (Hlywiak and Nolan, 2019) gave consistent results and showed that the effect of BLs strongly depend on the intensity (or stage) of the TC. For a TC of weak intensity, where most of the cooling arises from the surface heat fluxes, the BL shoals the OML and isolates it from the colder water below, thus making the surface heat extraction more efficient. For a TC of stronger intensity, where most of the cooling is due to shear instability and mixing at the base of the OML, the presence of the BL mitigates the efficiency of the mixing.

The upper-ocean salinity changes in the wake of a TC have motivated fewer studies than the surface cooling because of their indirect effect on the cyclone intensity. However, they can modulate the subsurface stratification and enhance or weaken the mixing or heat extraction. Sea surface salinity (SSS) changes result from the competing effects of precipitation and vertical shear and mixing near the base of the OML bringing saltier water up to the surface. Rain rates in TCs are a maximum of 35 to $50 \mathrm{~km}$ away from the storm centre, and their magnitudes range from 3 to $12 \mathrm{~mm} \mathrm{~h}^{-1}$ on average depending on the cyclone intensity (Lonfat et al., 2004). In a study of more than 800 TCs based on satellite observations and reanalysis of the upper-ocean characteristics, Jourdain et al. (2013) showed that, despite strong precipitation and neglecting the effect of evaporation, the wake of TCs is marked by salinization. Strong mixing brings saltier water from below the OML, overcompensating the freshening effect of rain. Note that, in this study, the SST cooling is attributed entirely to the turbulent mixing. A recent and more realistic study using in situ observations brought contrast to that. It showed that the freshening effect of strong precipitation dominates the salinizing due to mixing and evaporation at least in a $150 \mathrm{~km}$ radius around the cyclone centre (Steffen and Bourassa, 2018).

The cooling of the oceanic upper layer by extratropical storms or hybrid cyclones like medicanes has motivated fewer studies than for TCs probably because their magnitude is much smaller and there is supposedly no or very little feedback on the atmosphere. Indeed, coupled simulations of midlatitude storms in the North Atlantic showed that, in contrast with TCs where the cooling can reach several degrees, the mean effect is below $1{ }^{\circ} \mathrm{C}$ (Ren et al., 2004; Yao et al., 2008). A recent statistical study on North Pacific storms based on satellite observations and reanalysis over 20 years also gave a mean SST cooling of 1 order of magnitude smaller than what is obtained for TCs (Kobashi et al., 2019). Surface heat fluxes and turbulent mixing contributed equally to the cooling. Finally, a study of a strong storm in the Gulf of Lion in May 2005 using a coupled ocean-atmosphere-wave sim- 
ulation obtained a surface cooling of $2{ }^{\circ} \mathrm{C}$ over a large area (Renault et al., 2012). During this storm, the major contributor to the OML cooling was the vertical mixing enhanced by the strong surface stress $(68 \%)$ with secondary contributions from the latent and sensible heat fluxes $(15 \%$ and $7.5 \%$ of the cooling). These contributions are similar to those obtained in TCs of Category 2 or above.

In the present study, we use a coupled ocean-atmosphere kilometre-scale simulation to investigate the impact of the short but intense medicane Qendresa (7 November 2014) on the OML. Comparing the atmospheric processes of medicanes with those of TCs is a tempting but challenging undertaking. Indeed, no systematic statistical study provides, to the best of our knowledge, a comprehensive assessment of the processes at play according to the cyclone intensity, especially for categories 1 and 2, that could be compared with medicanes. Conversely, as detailed here above, the impact of TCs on the upper ocean and the corresponding mechanisms were the subject of systematic studies scanning the different TC categories (e.g. Vincent et al., 2012a; Jullien et al., 2014). We thus take advantage of this knowledge to contrast the coupling mechanisms and oceanic upper-layer processes in a medicane with those of TCs.

A first study of the life cycle and atmospheric processes of this medicane, including the assessment of the impact of the SST cooling on the atmosphere, showed that the surface cooling is at least 1 order of magnitude lower than in typical TCs (Bouin and Lebeaupin Brossier, 2020). The present study aims to investigate (i) how the surface cooling and/or salinity changes obtained in this case compare with changes observed in TCs or mid-latitude storms, (ii) whether the OML processes are similar to those of TCs, and (iii) whether the characteristics of the changes obtained here are modulated by the atmospheric forcing or by the central Mediterranean oceanic conditions prior to the medicane. Section 2 summarizes the case study and presents the oceanic conditions before the event and the numerical tools used in this work. The results, with the evolution of the ocean and an analysis of the role of the atmospheric forcing and of the mechanisms at play, are given in Sect. 3. Section 4 presents the impact of the oceanic conditions on the cooling and salinity changes in different areas. These results are discussed and conclusions are given in Sect. 5.

\section{Case study and simulations}

We present here a summary of the November 2014 medicane, the oceanic conditions that pre-exist in the central Mediterranean, and the ocean-atmosphere simulating configuration used in this study.

\subsection{The November 2014 medicane}

The November 2014 medicane has been extensively described in several case studies (Carrió et al., 2017; Pytharoulis, 2018; Cioni et al., 2018; Bouin and Lebeaupin Brossier, 2020); only a short summary of its life cycle is given here.

\subsubsection{Synoptic situation}

The medicane formed north of Lampedusa on the morning of 7 November from the conjunction of a baroclinic disturbance at low level and of upper-level instability. Strong convection developed in the morning with heavy precipitation (more than $150 \mathrm{~mm}$ locally) in the area of Sicily. The low-level system rapidly deepened with a sudden drop of sea-level pressure of $8 \mathrm{hPa}$ in $6 \mathrm{~h}$ and evolved into the quasi-circular structure of a tropical cyclone with spiral rain bands and a cloudless eye-like centre. The maximum intensity was reached around 12:00 UTC on 7 November north of Lampedusa with sustained $10 \mathrm{~m}$ wind speeds above $34 \mathrm{~m} \mathrm{~s}^{-1}$. Strong winds persisted during its transit towards the southern Sicilian coast with a landfall at Malta around 17:00 UTC. It reached Sicily in the evening of 7 November and continued its decay during the following night on the Ionian Sea close to the Sicilian coast until 12:00 UTC on 8 November. Three distinct phases of the event are described in Bouin and Lebeaupin Brossier (2020): the development phase with strong convection and a maximum of precipitation until 11:00 UTC on 7 November, when air-sea exchanges of heat and momentum were at a maximum; the mature phase until 18:00 UTC on the same day, with surface wind decaying but strong surface heat fluxes and heavy rain persisting; and the decay phase until 12:00 UTC on 8 November, when surface exchanges rapidly decreased. The same study shows that the surface heat transfer throughout the event is mainly controlled by the surface wind and the SST.

The trajectory of the simulated event is given in Fig. 1, as well as the bathymetry on the domain of the study (see Cioni et al., 2018, and Fig. 2 of Bouin and Lebeaupin Brossier, 2020 , to compare to the best track obtained from satellite data analysis).

\subsubsection{Oceanic conditions}

The simulation after a spin-up of 4 hours is used here to describe the oceanic conditions prevailing at the beginning of the event.

The simulated medicane spent most of its lifetime in the Strait of Sicily area, which is significantly shallower than the surrounding basins with a mean bathymetry close to $500 \mathrm{~m}$. Also, large coastal areas are shallower than $100 \mathrm{~m}$, for instance in the Gulf of Gabès. This shallow bathymetry makes the area very sensitive to surface forcing and lateral advection. As a transition between the western and east- 


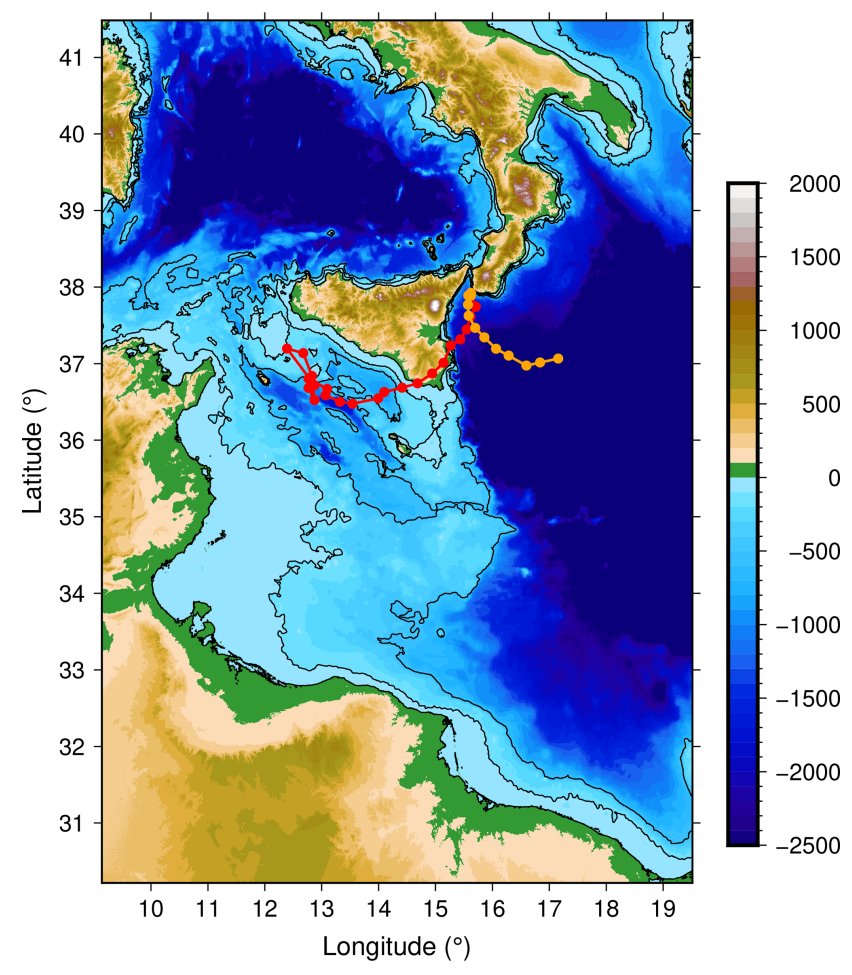

Figure 1. Map of the domain and bathymetry (m) used in the coupled simulation. The contours indicate the 100 and $500 \mathrm{~m}$ isobaths. The track of the simulated medicane is indicated in red until 00:00 UTC on 8 November and in orange after that.

ern Mediterranean, the region is characterized by large-scale gradients (Drago et al., 2010): a north-south thermal gradient and a west-east salinity gradient between Atlantic Water flowing eastwards along the Tunisian coast (AW; 0 to $100 \mathrm{~m}$ depth, $T=15-17^{\circ} \mathrm{C}, S=37.2-37.8$ with a salinity minimum around $50 \mathrm{~m}$ ) and Ionian Water (from 50 to $100 \mathrm{~m}$ depth, $T=15-16.5^{\circ} \mathrm{C}, S=37.8-38.4$ ). These two water masses cap the Levantine Intermediate Water (LIW; with a core depth of $300 \mathrm{~m}, T=13.75-13.92^{\circ} \mathrm{C}, S=38.73-$ 38.78) that originates from the thermohaline circulation in the eastern basin and flows westwards. These gradients are well represented in the surface initial conditions used in this study (Figs. 2 and 3b). North of the Strait of Sicily, the SST is below $21^{\circ} \mathrm{C}$, while it reaches $24^{\circ} \mathrm{C}$ close to the Libyan coast. This marked SST contrast has been shown to largely control the surface heat fluxes during the most intense part of the event along with the surface wind speed (Bouin and Lebeaupin Brossier, 2020). In the Tyrrhenian Sea and the Strait of Sicily, the SSS is below 38 with a strong impact of the AW flowing eastwards along the Tunisian coast (the AW flow can also be seen on the SST map).

When comparing the model initial SSTs (at 01:00 UTC on 7 November) with those provided by a satellite analysis at 00:00 UTC on 7 November, the model SSTs are biased low at $-0.63 \pm 0.49^{\circ} \mathrm{C}$, but the general patterns are well repre-
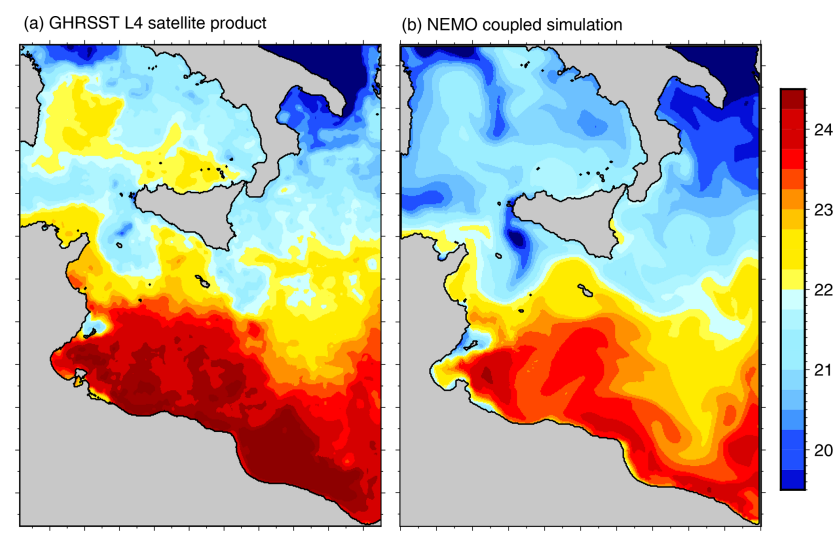

Figure 2. Map of the SST $\left({ }^{\circ} \mathrm{C}\right)$ in the GHRSST L4 satellite product at 00:00 UTC (a) and in the output of the Nucleus for European Modelling of the Ocean (NEMO) simulation at 01:00 UTC (b) on 7 November.
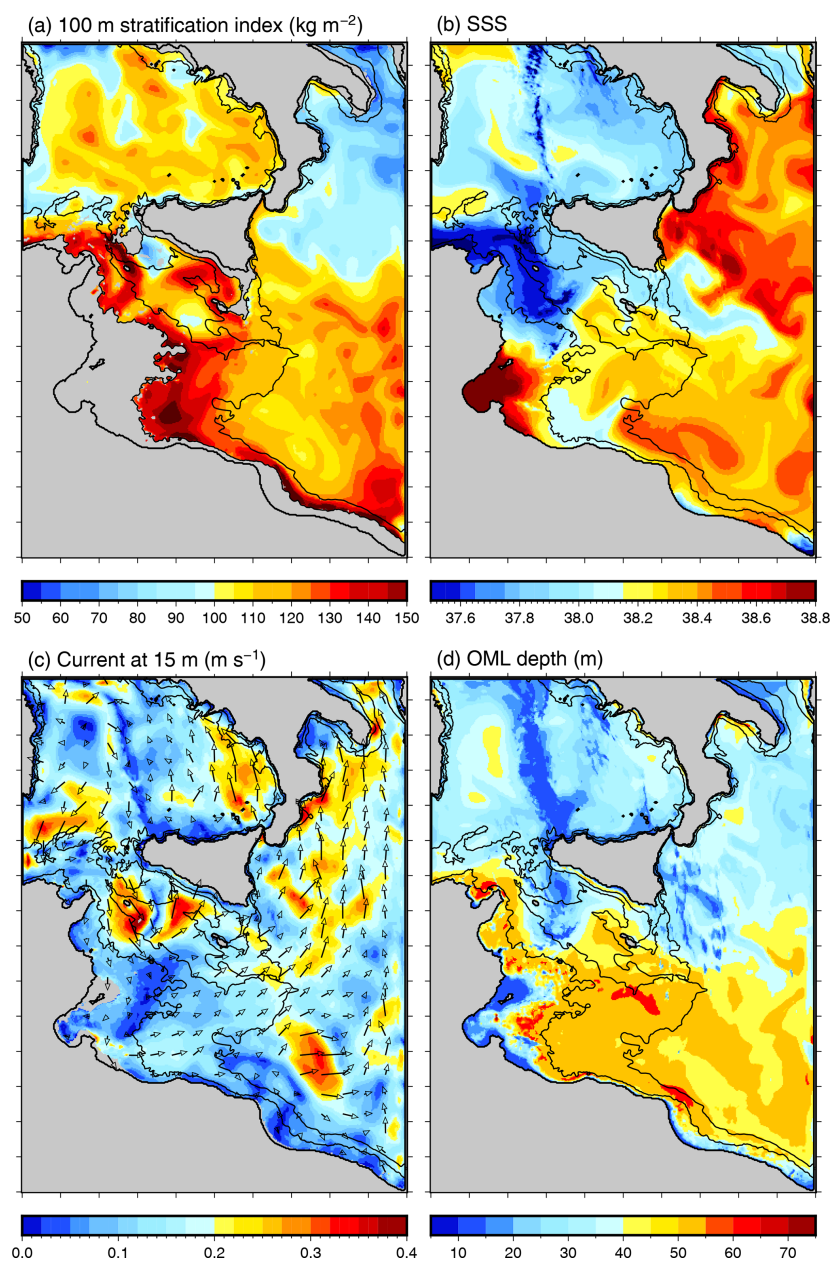

Figure 3. Map of the stratification index (SI) at $100 \mathrm{~m}$ (a), SSS (b), current at $15 \mathrm{~m}$ (c), and mixed layer depth (d) at the beginning of the simulation (04:00 UTC on 7 November). The black contours indicate the 100 and $500 \mathrm{~m}$ isobaths 
sented with a correlation coefficient $\left(r^{2}\right)$ of 0.86 (note that the uncertainties, here and below in the text, correspond to 1 standard deviation or $68 \%$ ).

On average for this area, the climatology from d'Ortenzio et al. (2005) gives MLDs of $15-30$ and 40-50 $\mathrm{m}$ in October and November, respectively. This is consistent with the MLD at the beginning of the simulation (Fig. 3d) between 10 and $40 \mathrm{~m}$ in the Tyrrhenian and Ionian seas and between 40 and $50 \mathrm{~m}$ in most of the Strait of Sicily and north of Libya. Note that the MLD used in this study is defined as the depth where the density is equal to $\rho_{0}+\Delta \rho_{\mathrm{c}}$, with $\rho_{0}=\rho_{-10}$ being the density at $10 \mathrm{~m}$ for each grid point and $\Delta \rho_{\mathrm{c}}$ being the density criterion of $0.10 \mathrm{~kg} \mathrm{~m}^{-3}$ here.

The surface circulation (Fig. 3c) shows a large mesoscale variability with coastal jets, gyres, meanders, and filaments (Poulain and Zambianchi, 2007; Ciappa, 2009). These structures are generated by perturbations induced by tidal, inertial, gravity, surface and continental shelf waves, and nonlinear interactions with bathymetry and/or by synoptic-scale atmospheric forcing and local wind regimes (Hamad et al., 2006; Omrani et al., 2016). Several eddies are supposed to be present regularly like the cyclonic eddy south-west of Sicily (Adventure Bank Vortex, ABV hereafter; Sorgente et al., 2011) and the anticyclonic Sorgente gyre north of the Libyan coast, also visible here. The ABV is marked by SSTs significantly colder than the surrounding area $\left(20.0 \pm 0.4^{\circ} \mathrm{C}\right.$ with respect to $21.5 \pm 0.5^{\circ} \mathrm{C}$ ). The $\mathrm{OML}$ in the eddy is also shallower than in the rest of the Strait of Sicily at $20 \pm 4 \mathrm{~m}$ with respect to $36 \pm 11 \mathrm{~m}$ elsewhere.

The stratification index (SI) used in this study is computed as in the work of Estournel et al. (2016) as the amount of buoyancy (in $\mathrm{kg} \mathrm{m}^{-2}$ ) to be extracted to mix the water column from the surface to level $z$ (here $-100 \mathrm{~m}$, chosen to represent the stratification of the surface layer) and to achieve a homogeneous density $\rho$ :

$\mathrm{SI}_{-100}=\int_{-100}^{0}(\rho(-100)-\rho(z)) \mathrm{d} z$.

At the beginning of the simulation (Fig. 3a), the stratification is pronounced in the Strait of Sicily with the influence of the AW ( $\mathrm{SI}=125 \pm 14 \mathrm{~kg} \mathrm{~m}^{-2}$ ) and weaker in the Ionian Sea $\left(92 \pm 11 \mathrm{~kg} \mathrm{~m}^{-2}\right)$. Minimum values of MLD are visible on the Tunisian continental shelf (around the Gulf of Gabès with a depth less than $30 \mathrm{~m}$; see Fig. 1). Continental shelf waters are known to be significantly more sensitive to atmospheric conditions (Béjaoui et al., 2019) with wind-induced mixing that quickly homogenizes the water column and salinity reacting instantaneously to evaporation, runoff, or heavy rain (Ben Ismail et al., 2017).

\subsection{Numerical settings and tools}

The ocean-atmosphere coupled numerical simulation of the event was performed using the state-of-the-art atmospheric model Meso-NH (Lac et al., 2018) and oceanic model Nucleus for European Modelling of the Ocean (NEMO) (Madec and the NEMO team, 2015).

\subsubsection{Atmospheric model}

The non-hydrostatic French research model Meso-NH version 5.3.0 is used in the present study with numerical and physical packages as described in Bouin and Lebeaupin Brossier (2020). The radiative transfer is computed by solving long-wave and short-wave radiative transfers separately using the European Centre for Mediumrange Weather Forecasts (ECMWF) operational radiation code (Morcrette, 1991). The sea surface fluxes are computed within the SURFEX module (Surface Externalisée; Masson et al., 2013) using the iterative bulk parameterization ECUME (Belamari, 2005; Belamari and Pirani, 2007) linking the surface turbulent fluxes to the meteorological gradients and the SST through the appropriate transfer coefficients. The Meso-NH model shares its physical representation of parameters, including the surface flux parameterization, with the French operational model AROME used for Météo-France weather prediction with a horizontal resolution of $1.3 \mathrm{~km}$ (Seity et al., 2011). In the present study, a first atmosphere-only simulation at the horizontal resolution of $4 \mathrm{~km}$ has been run on a larger domain of $3200 \mathrm{~km} \times 2300 \mathrm{~km}$ (not shown here) to provide initial and boundary conditions for the simulation at $1.33 \mathrm{~km}$ on a smaller domain of $900 \mathrm{~km} \times 1280 \mathrm{~km}$ (Fig. 1). This run at coarser resolution started at 18:00 UTC on 6 November and lasted $42 \mathrm{~h}$ until 12:00 UTC on 8 November. Its initial and boundary conditions come from the ECMWF operational analyses every $6 \mathrm{~h}$. The coupled simulation on the inner domain that is used here to investigate the oceanic evolution starts at 00:00 UTC on 7 November and lasts until 12:00 UTC on 8 November.

\subsubsection{Oceanic model}

The ocean model used is NEMO (version 3.6) with physical parameterizations as follows. The total variance dissipation scheme is used for tracer advection in order to conserve energy and enstrophy (Barnier et al., 2006). The vertical diffusion follows the standard turbulent kinetic energy formulation of NEMO (Blanke and Delecluse, 1993). In the case of unstable conditions, a higher diffusivity coefficient of $10 \mathrm{~m}^{2} \mathrm{~s}^{-1}$ is applied (Lazar et al., 1999). The sea surface height (SSH) is a prognostic variable solved thanks to the filtered free-surface scheme of Roullet and Madec (2000). A no-slip lateral boundary condition is applied, and the bottom friction is parameterized by a quadratic function with a coefficient depending on the 2D mean tidal energy (Lyard et al., 2006; Beuvier et al., 2012). The diffusion is applied along iso-neutral surfaces for the tracers using a Laplacian operator with the horizontal eddy diffusivity value $\nu_{\mathrm{h}}$ of $30 \mathrm{~m}^{2} \mathrm{~s}^{-1}$. 
For the dynamics, a bi-Laplacian operator is used with the horizontal viscosity coefficient $\eta_{\mathrm{h}}$ of $-1 \times 10^{9} \mathrm{~m}^{4} \mathrm{~s}^{-1}$.

The configuration used here is subregional and eddyresolving with a $1 / 36^{\circ}$ horizontal resolution over an ORCA grid (from 2 to $2.6 \mathrm{~km}$ resolution) named SICIL36 (tri-polar grid with variable resolution; Madec and Imbard, 1996) that was extracted from the MED36 configuration domain (Arsouze et al., 2013) and shares the same physical parameterizations with its "sister" configuration WMED36 (Lebeaupin Brossier et al., 2014; Rainaud et al., 2017). It uses 50 stretched $z$ levels in the vertical with level thickness ranging from $1 \mathrm{~m}$ near the surface to $400 \mathrm{~m}$ at the sea bottom (i.e. around $4000 \mathrm{~m}$ depth) and a partial step representation of the bottom topography (Barnier et al., 2006). It has four open boundaries corresponding to those of the domain shown in Fig. 1, and its time step is $300 \mathrm{~s}$. The open boundary conditions come from the global $1 / 12^{\circ}$ resolution PSY2V4R4 daily analyses from Mercator Océan International (Lellouche et al., 2013) also used as initial conditions at 00:00 UTC on 7 November.

\subsubsection{Configuration of the coupled simulation}

The coupled simulation between the Meso-NH and NEMOSICIL36 models relies on the SURFEX-OASIS coupling interface developed by Voldoire et al. (2017). The two components of the momentum flux, the solar and non-solar heat fluxes, and the freshwater flux are transmitted from the atmospheric model to the oceanic model every $15 \mathrm{~min}$. This high coupling frequency was chosen to take into account the rapid evolution of the event simulated with Meso-NH in $36 \mathrm{~h}$ (see the track in Fig. 1). The oceanic model exports the SST and two components of the surface current into the atmospheric model at the same time step. As this fully coupled configuration was used for a previous study of medicane evolution and the impact of the coupling on the atmosphere (Bouin and Lebeaupin Brossier, 2020), we did not consider using an oceanic simulation forced by the atmosphere. Since the impact of time evolution of the SST on the atmosphere evaluated in this previous study is very weak, it is likely that using a forced simulation here would lead to the same results. Examining the time evolution of the oceanic parameters in the first hours of the simulation shows that there is a spin-up effect of the model with a strong adjustment of the ocean upper layer in the first hour. In the present study, we consider the evolution of the oceanic parameters after 01:00 UTC on 7 November.

\section{Atmospheric forcings, evolution of the ocean, and processes}

\subsection{Atmospheric forcings}

Here are described the characteristics and time evolution of the atmospheric forcings as seen by the ocean model. Among
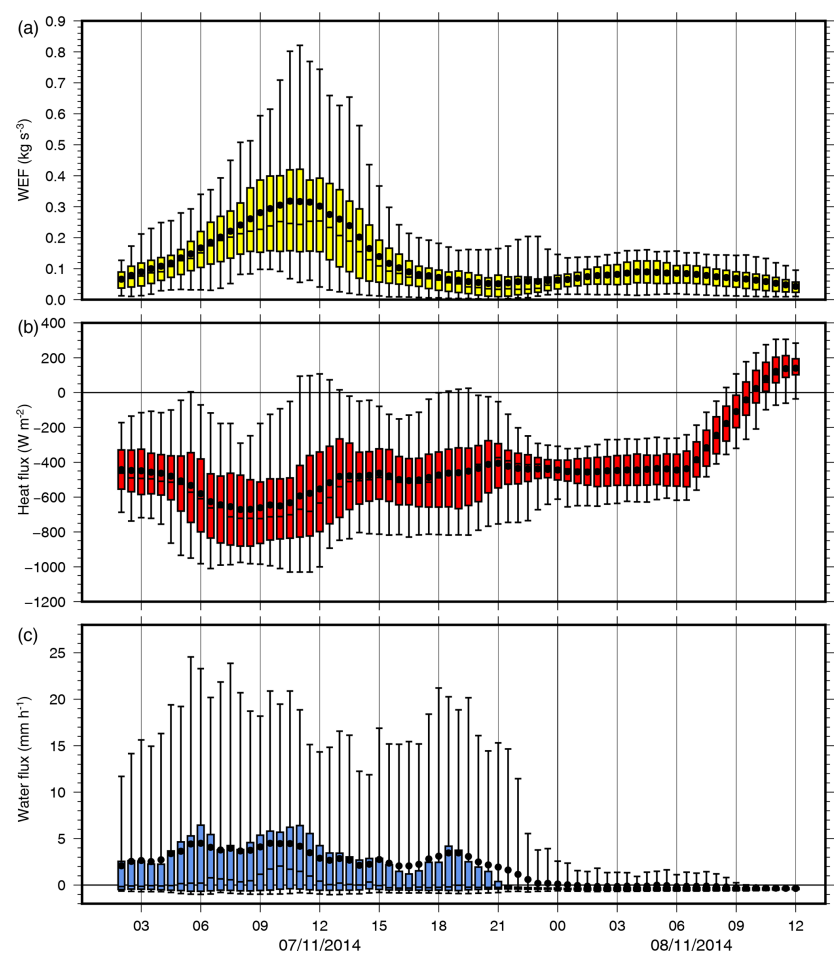

Figure 4. Time series of the median values of the wind energy flux (a), net heat flux (b), and water flux (positive values correspond to precipitation) (c) in the SFA. The boxes correspond to the $25 \%$ and $75 \%$ quantiles and the whiskers to the $5 \%$ and $95 \%$ quantiles. The solid black dots correspond to the mean values.

the forcing parameters, the solar and non-solar heat fluxes (heat fluxes hereafter) include the turbulent fluxes (latent and sensible heat fluxes). The water flux corresponds to precipitation minus evaporation, and a positive water flux corresponds therefore to freshwater input into the ocean.

Because of the small size and short duration of the event, the methodology commonly used in TC studies (i.e. averaging values on circles of $500 \mathrm{~km}$ around the cyclone centre or contrasting mean SST values $3 \mathrm{~d}$ after and before the cyclone) is not appropriate here. Instead, we define and use in the following a strong flux area (SFA) as the area where both the accumulated surface heat fluxes and the accumulated wind energy flux injected into the ocean at 07:00 UTC on 8 November are above their $80 \%$ quantiles (this time corresponds to the end of the period of intense forcing; see Fig. 4). The wind energy flux (WEF) is defined here as the scalar product of the wind stress by the surface currents (see Giordani et al., 2013, for a similar use). The threshold values are $-42.8 \mathrm{MJ} \mathrm{m}^{-2}$ and $7.59 \times 10^{3} \mathrm{~kg} \mathrm{~s}^{-2}$, respectively. Only the model grid points with bathymetry deeper than $100 \mathrm{~m}$ and located in the Strait of Sicily are kept, and this results in 6574 points (see Fig. 6).

Over the SFA, the upward surface heat flux intensifies until 09:00 UTC on 7 November (median value $-723 \mathrm{~W} \mathrm{~m}^{-2}$, 
$5 \%$ and $95 \%$ quantiles -117 and $-985 \mathrm{~W} \mathrm{~m}^{-2}$ ) and decays slowly after that (Fig. 4a). Its median value stays close to $-400 \mathrm{~W} \mathrm{~m}^{-2}$ until 06:00 UTC on 8 November but with less spreading and no value below $-800 \mathrm{~W} \mathrm{~m}^{-2}$. After 06:00 UTC on 8 November, the turbulent fluxes extracting heat are close to 0 , and the solar flux is strong again, making the net heat flux increase rapidly to positive values.

Conversely, the WEF grows continuously until 11:0012:00 UTC (time of the maximum intensity of the medicane; Fig. 4) with a median value of $0.25 \mathrm{~kg} \mathrm{~s}^{-3}$ and a $95 \%$ quantile of $0.74 \mathrm{~kg} \mathrm{~s}^{-3}$. After that time, it drops more quickly than the heat flux and stays around $0.1 \mathrm{~kg} \mathrm{~s}^{-3}$ from 15:00 UTC on 7 November.

The time evolution of the water flux in the SFA is largely dominated by precipitation until 21:00 UTC on 7 November (Fig. 4c). Conversely to the heat and momentum fluxes where the distributions are almost symmetrical (the mean and median values almost coincide), the water flux distribution is strongly asymmetric towards the highest values on 7 November. The largest water flux in mean and median values occurs at 10:00 UTC on 7 November $\left(4.6\right.$ and $2.0 \mathrm{~mm} \mathrm{~h}^{-1}$, respectively). Conversely, the highest water flux (95\% quantile) occurs before 06:00 UTC on 7 November with a 30 min averaged value of $24.8 \mathrm{~mm} \mathrm{~h}^{-1}$.

In the SFA, the time evolution of the heat fluxes, WEF, and water flux is in contrast to what is generally observed in TCs. The maximum sustained wind speed of Qendresa makes it comparable to a Category 1 TC on the Saffir-Simpson scale. The values of the heat fluxes exceed values usually obtained for Category 1 TCs (e.g. Wroe and Barnes, 2003; Zhang et al., 2008; Kowaleski and Evans, 2015). They peak earlier than the WEF and stay above $400 \mathrm{~W} \mathrm{~m}^{-2}$ for more than $24 \mathrm{~h}$. The water flux is strong and always positive with values comparable to Category 2 TCs. Heavy rainfall occurring in the early hours of 7 November results in a freshwater input of around $5 \mathrm{~mm} \mathrm{~h}^{-1}$ until 10:00 UTC.

\subsection{Sea surface cooling and salinity change}

The mean values of the SST, SSS, potential temperature $(\Delta\langle\theta\rangle)$, and salinity $(\Delta\langle S\rangle)$ changes in the OML, as well as the changes in MLD and SI for the first $24 \mathrm{~h}$ of the simulation in the SFA, are given in Table 2. Some additional values (related to Figs. 5 and 6) are given in the text.

In the simulation, the studied domain is affected by an overall weak surface cooling of $-0.18 \pm 0.21{ }^{\circ} \mathrm{C}$ over the first $24 \mathrm{~h}$ (Fig. 5b). A comparison of the SST change with satellite observations from the Group for High-Resolution SST (GHRSST) L4 products (Piolle et al., 2010) shows an overestimation of the cooling by the model (mean bias of $-0.26 \pm 0.22{ }^{\circ} \mathrm{C}$; see Fig. 5). The largest surface cooling is obtained south-east of the Strait of Sicily between the north of Tunisia and the south of Sicily where the medicane spent several hours with low translation speed and strong air-sea surface exchanges on the morning of 7 November. In the
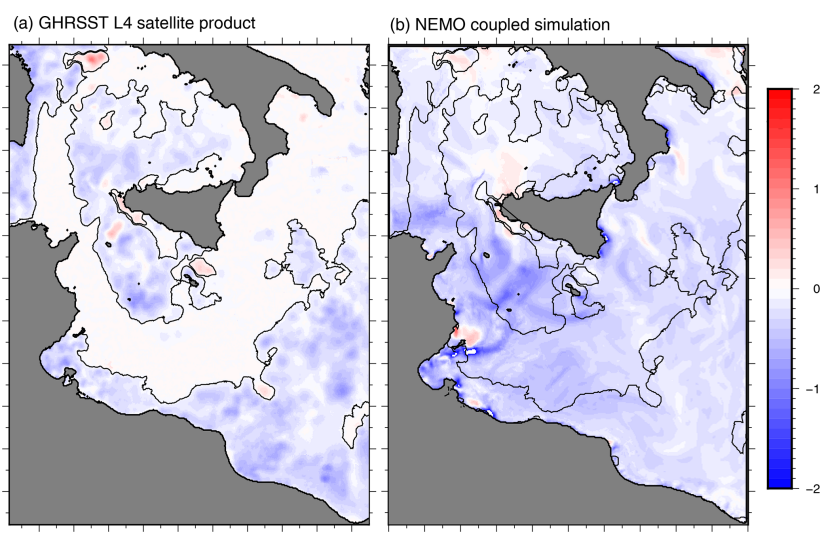

Figure 5. Map of the SST difference after $24 \mathrm{~h}\left({ }^{\circ} \mathrm{C}\right)$ in the GHRSST L4 satellite product (a) and in the output of the NEMO simulation (b). The white areas in (a) indicate the lack of satellite observations, which are reported also in (b) for a better comparison.

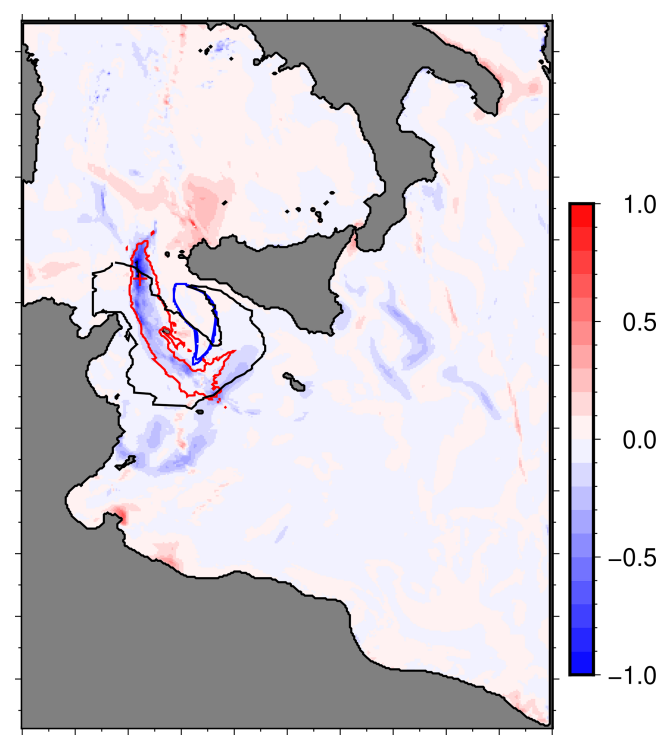

Figure 6. Map of the surface salinity difference at 00:00 UTC on 8 November with respect to the beginning of the simulation. The black contours indicate the strong flux area, the blue contour the EDDY area, and the red contour the heavy rain (HR) area.

SFA, the mean SST cooling at 00:00 UTC on 8 November is $-0.56 \pm 0.24^{\circ} \mathrm{C}$ (maximum $-1.37^{\circ} \mathrm{C}$, minimum $0.20^{\circ} \mathrm{C}$ ), and the mean cooling of the OML is $-0.54 \pm 0.23^{\circ} \mathrm{C}$. The evolution of the salinity within the OML shows more contrast with a very weak median change of -0.010 over the whole domain, a $5 \%$ quantile positive change of 0.053 , and a $95 \%$ quantile negative change (freshening) of -0.110 . The SSS is almost constant on average (change in salinity of $-8.3 \times 10^{-3}$ ) with a strong spatial variability (Fig. 6). The overall effect is therefore a freshening with some areas of salinification north-west of Sicily and along the coast of Tunisia, for instance in the shallow area north of the Gulf 
of Gabès where the evaporation is very efficient. The OML freshening is dominant in the SFA with a mean value of -0.07 , a maximum positive change ( $5 \%$ quantile) of 0.03 , and a maximum negative change (95\% quantile) of -0.20 . Within the SFA, the spatial variability of the salinity change is also substantial.

The SST cooling obtained here is lower than for TCs of Category 1 for which wakes 1 to $2^{\circ} \mathrm{C}$ colder than the surrounding ocean are currently observed (e.g. Vincent et al., 2012a). The weak surface freshening we obtain is rather consistent with the work of Steffen and Bourassa (2018) based on Argo observations showing that within $200 \mathrm{~km}$ around the TC centre, freshening overcomes salinification in every basin. This freshening occurs early in the medicane life cycle, with two-thirds of the final value reached at 12:00 UTC on 7 November due to the strong precipitation on the morning of 7 November. Note that no observation of vertical profiles of salinity or temperature is available close to the medicane track for the period of the event. A direct validation of the oceanic modelling is therefore not possible. Nevertheless, the previous study of this medicane showed that the same configuration reproduces satisfactorily the intensity and time evolution of the medicane with a mean northward shift of its track of $85 \mathrm{~km}$, thus validating the atmospheric part of this simulation (Bouin and Lebeaupin Brossier, 2020).

\subsection{Oceanic processes}

This part describes the simulated OML processes obtained throughout the event with reference to the processes commonly observed in TCs. As seen in Sect. 2.1.2, the SFA represents a strongly dynamic region with large horizontal gradients of temperature and salinity, strong currents, and the presence of the ABV cyclonic eddy. The stratification index in the SFA is high at the beginning of the simulation with values of $125 \pm 14 \mathrm{~kg} \mathrm{~m}^{-2}$ except in the ABV cold eddy $\left(88 \pm 14 \mathrm{~kg} \mathrm{~m}^{-2}\right.$; Fig. 3; Table 1). The MLD is $34 \pm 11 \mathrm{~m}$ around the eddy and 16 $\pm 3 \mathrm{~m}$ in the eddy itself. At 13:00 UTC on 7 November, the cyclonic circulation at $15 \mathrm{~m}$ within the eddy is reinforced due to strong wind stress with a marked diverging component and maximum velocities between 0.7 and $0.8 \mathrm{~m} \mathrm{~s}^{-1}$. As a consequence of this subsurface divergence, the sea surface height decreases by $10 \mathrm{~cm}$ in the eddy centre, and strong upward motions develop under the OML at around $50 \mathrm{~m}$ depth. The strong shear resulting from the horizontal currents close to the bottom of the OML generates violent mixing which brings colder water from below the thermocline up. The upwelling is at a maximum at 15:00 UTC with an ascent of the thermocline of $5 \mathrm{~m}$ and a lowering of the SSH by $17 \mathrm{~cm}$. Following this, vertical oscillations are established with a period close to $19 \mathrm{~h}$ (the inertial period for this area is between 20.5 and $21 \mathrm{~h}$ ). At 00:00 UTC on 8 November, the amplitude of the subsurface cyclonic circulation has returned to its initial value but with a marked converging component. At that time, the vertical velocity under the OML is negative, and the SSH is still $10 \mathrm{~cm}$ depressed. The OML is deeper at the eddy centre, and shallower around the outer edge of the eddy.

The processes obtained are similar to those observed in TCs. To assess the respective roles of the surface heat fluxes and of the turbulent mixing in the time evolution of the OML, we performed a budget analysis of the temperature and salinity in the OML using the equation of the tracer tendency as in Vialard and Delecluse (1998). The tendency of a given tracer $X(\theta$ or $S)$ within the OML is given by

$$
\begin{array}{rlrl}
h \frac{\partial\langle X\rangle}{\partial t}= & \mathcal{F}^{X} & & {[\mathrm{FOR}] \times h} \\
& -h\langle\boldsymbol{U} \cdot \nabla X\rangle & & {[\mathrm{h}-\mathrm{ADV}] \times h} \\
& -\mathrm{w}_{(z=-h)}\left(\langle X\rangle-X_{(z=-h)}\right) & & \\
& + & h\left(\frac{\partial}{\partial x}\left(A^{\mathrm{h}} \frac{\partial\langle X\rangle}{\partial x}\right)+\frac{\partial}{\partial y}\left(A^{\mathrm{h}} \frac{\partial\langle X\rangle}{\partial y}\right)\right. & \\
& \left.+\frac{\partial}{\partial z}\left(A^{\mathrm{v}} \frac{\partial\langle X\rangle}{\partial z}\right)\right) & & \\
& -\left(\frac{\partial h}{\partial t}+\boldsymbol{U} \cdot \nabla h=0\right)\left(\langle X\rangle-X_{(z=-h)}\right) & \\
& +\overline{w^{\prime} X^{\prime}}(z=-h), & & {[\mathrm{ENTR}] \times h}
\end{array}
$$

where $h$ is the MLD, $\boldsymbol{U}$ is the horizontal velocity vector, and w is the vertical velocity. $A^{\mathrm{h}}$ and $A^{\mathrm{v}}$ are the horizontal and vertical eddy diffusivity coefficients $\left(\mathrm{m}^{2} \mathrm{~s}^{-1}\right), \mathcal{F}^{X}$ is the surface flux, and $\overline{\mathrm{w}^{\prime} X^{\prime}}$ is the turbulent flux of tracer $X$. Finally, $\langle X\rangle=\frac{1}{h} \int_{-h}^{0} X \mathrm{~d} z$.

From that, the different terms of the temperature and salinity tendencies can be deduced.

- The surface forcing term (FOR) corresponds to the net heat flux for the potential temperature $\langle\theta\rangle$ (shortwave and longwave radiative net fluxes plus latent and sensible heat fluxes) and to the water flux for the salinity.

- The horizontal advection (h-ADV) can be decomposed into zonal (ADV-X) and meridional (ADV-Y) advections.

- The vertical advection is across the OML (v-ADV).

- The diffusion term (DIF) can be decomposed into lateral and vertical diffusions, this latter term corresponding to the turbulent mixing within the OML (TM hereafter).

- The residual term (ENTR) is linked to the variations of the surface defined by $z=-h$ and to the turbulent mixing at the base of the OML.

More details and additional examples of applications can be found in the work of Lebeaupin Brossier et al. (2013) and Lebeaupin Brossier et al. (2014).

These tendency terms are used in the following to quantify the processes controlling the evolution of the temperature and salinity within the OML.

\subsubsection{Temperature tendency}

The time evolution of tendency terms for $\langle\theta\rangle$ in the SFA is given in Fig. 7 with the corresponding evolution of $\langle\theta\rangle$. 
Table 1. Oceanic parameters at the beginning of the simulation (04:00 UTC on 7 November) in the different zones (see text).

\begin{tabular}{lrrrr}
\hline & SFA & EDDY & HR & REF \\
\hline SST $\left({ }^{\circ} \mathrm{C}\right)$ & $21.5 \pm 0.5$ & $20.0 \pm 0.4$ & $21.5 \pm 0.4$ & $21.6 \pm 0.5$ \\
$\langle\theta\rangle\left({ }^{\circ} \mathrm{C}\right)$ & $21.4 \pm 0.5$ & $19.9 \pm 0.4$ & $21.4 \pm 0.4$ & $21.5 \pm 0.5$ \\
SSS & $37.68 \pm 0.17$ & $37.82 \pm 0.05$ & $37.61 \pm 0.12$ & $37.73 \pm 0.17$ \\
$\langle S\rangle$ & $37.88 \pm 0.15$ & $38.01 \pm 0.04$ & $37.82 \pm 0.12$ & $37.91 \pm 0.17$ \\
MLD (m) & $33.8 \pm 11.3$ & $16.2 \pm 2.8$ & $28.9 \pm 9.1$ & $36.5 \pm 11.3$ \\
BLT $(\mathrm{m})$ & $7.5 \pm 4.6$ & $8.0 \pm 2.3$ & $10.6 \pm 4.8$ & $6.1 \pm 3.9$ \\
SI $\left(\mathrm{kg} \mathrm{m}^{-2}\right)$ & $125 \pm 14$ & $88 \pm 14$ & $126 \pm 16$ & $125 \pm 12$ \\
\hline
\end{tabular}

The continuous decrease in $\langle\theta\rangle$ throughout the simulation is mainly due to the surface forcing FOR. The evolution of this FOR term mimics the one of the median and mean values of heat fluxes in the SFA (Fig. 4b) with a maximum at 09:00 UTC. The TM evolution is closer to the evolution of the median value of the WEF (Fig. 4a) with a maximum between 10:00 and 12:00 UTC on 7 November. Other significant contributions to the thermal evolution of the OML are from the lateral advection terms ADV-X and ADV-Y, which contribute to alternatively cool and warm the OML with a time period driven by the quasi-inertial oscillation. The vertical advection, lateral diffusion, and entrainment terms do not contribute significantly. At 10:00 UTC on 7 November, where the cooling tendency is at a maximum in the SFA, the relative contributions of FOR and TM are -0.53 and $-0.22{ }^{\circ} \mathrm{Cd}^{-1}$, respectively, representing $53 \%$ and $22 \%$ of the cooling. The accumulated contributions to the cooling of the OML at 12:00 UTC on 8 November represent $65 \%$ for FOR, $14 \%$ for TM, and $18 \%$ for the horizontal advection. In contrast with what is observed in intense TCs, the surface forcing is key here, the turbulent mixing playing only a secondary role like the lateral advection. The time evolution of the distribution of the FOR and TM terms for temperature in the SFA (Fig. 8) shows that all the quantiles of FOR are higher than those of TM. During the development phase and the beginning of the mature phase of the medicane (between 06:00 and 12:00 UTC on 7 November), TM even contributes to warm the OML for $25 \%$ of the SFA. This is the consequence of the ascent of the MLD due to a surface salinity change. This is discussed in more detail in Sect. 3.3.2. Due to the time lag between the peaks of the heat flux and of the WEF, FOR continues to significantly cool the OML until 09:00 UTC on 8 November.

The spatial distribution of the cooling due to FOR and to TM within the SFA is also different. A snapshot at 10:00 UTC on 7 November when the effect of TM is at a maximum (Fig. 9) shows the values of the FOR and TM terms for temperature averaged on radial bins around the medicane centre. The turbulent mixing effect is stronger than the surface forcing one within $20 \mathrm{~km}$ around the medicane centre, but it drops rapidly and becomes small after $200 \mathrm{~km}$. Conversely, the effect of FOR stays above $-0.2^{\circ} \mathrm{C}$ within
$500 \mathrm{~km}$ around the centre. This peak of the TM at the cyclone centre is likely due to the upwelling effect as the vertical velocity at $50 \mathrm{~m}$ shows a similar peak of $0.35 \mathrm{~mm} \mathrm{~s}^{-1}$ at that time.

The lateral advection contributes to alternatively cool and warm the OML (Fig. 7a) in phase with the near-inertial oscillation. From 00:00 UTC on 7 November till 12:00 UTC on 8 November, both ADV-X and ADV-Y cool the OML by $-0.12^{\circ} \mathrm{C}$ or $16 \%$ of the total cooling. A compensating warming effect of $\mathrm{ADV}$-X corresponds to $0.06^{\circ} \mathrm{C}$.

These results are consistent with those of the statistical study of Vincent et al. (2012a). First, the relative part of the surface forcing is higher than that of the turbulent mixing, as expected for the weakest TCs (70\% for FOR for TCs of Category 1 or below). Second, turbulent mixing and surface fluxes contribute equally within 2 radii of maximum wind, but surface fluxes dominate outside of that and concern a wider area. A case study in the Gulf of Mexico also showed that the surface heat fluxes induce a widespread, moderate cooling affecting the whole surface of the gulf, while vertical mixing results in a relatively stronger, more localized cooling around the cyclone centre (Morey et al., 2006). Third, the lateral advection contributes significantly to the cooling (and weakly to the following warming). This latter effect is likely due to the strong dynamics and horizontal gradients of the Strait of Sicily.

In the following, we document the time evolution of the salinity in the OML.

\subsubsection{Salinity tendency.}

The time evolution of the OML salinity tendency terms in the SFA is given in Fig. 10 with the corresponding evolution of the OML mean salinity and of the precipitation. The overall effect is a slight freshening until 21:00 UTC on 7 November as long as the precipitation rate is above $2 \mathrm{~mm} \mathrm{~h}^{-1}$. This freshening is thus due to the FOR term and is partly compensated by TM and, as secondary processes, by the horizontal advection and entrainment. This compensating effect drops rapidly after 12:00 UTC on 7 November with the decrease in the WEF (Fig. 4), whereas the surface forcing generates freshening until 21:00 UTC. In addition, the large amount of precipitation in the early hours of 7 November deepens the 


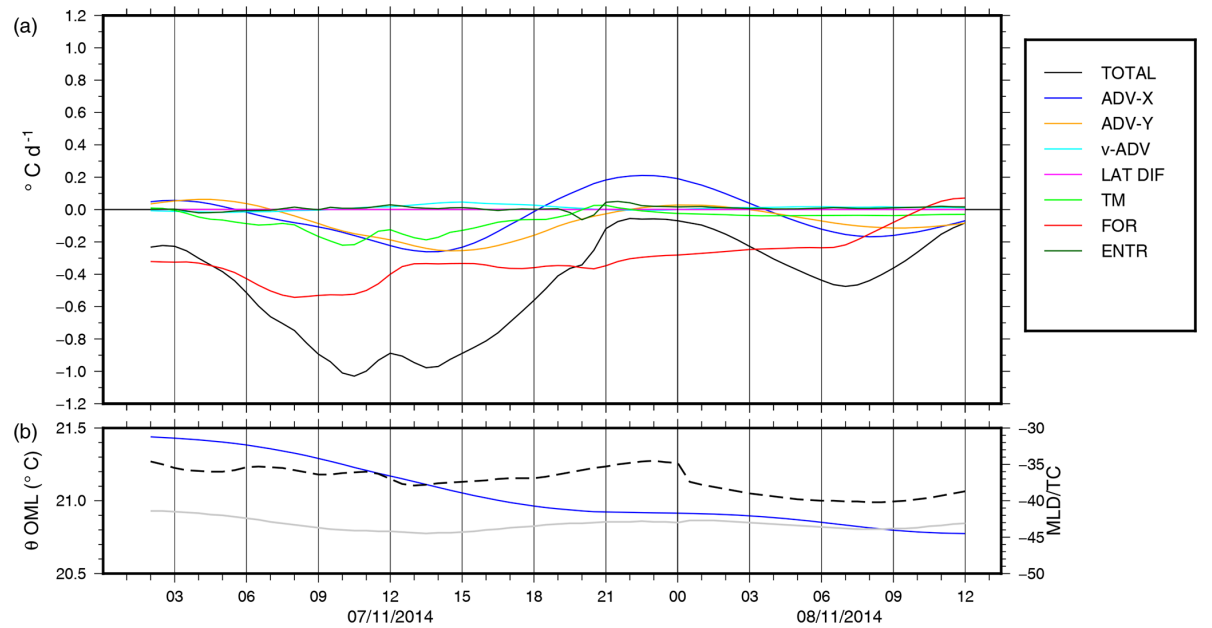

Figure 7. Time series of the different components of the tendency in the evolution of the potential temperature in the OML and in the SFA (a, colours) and the time evolution of the temperature in the OML (blue), of the MLD (dashed black), and of the $T_{-10 \mathrm{~m}}-0.3^{\circ} \mathrm{C}$ thermocline (grey) in the SFA (b). The terms represented are horizontal advection (ADV-X and ADV-Y), the vertical advection v-ADV, the lateral diffusion LAT DIFF, the turbulent mixing TM, the surface heat forcing FOR and the entrainment at the bottom of the OML (ENTR).
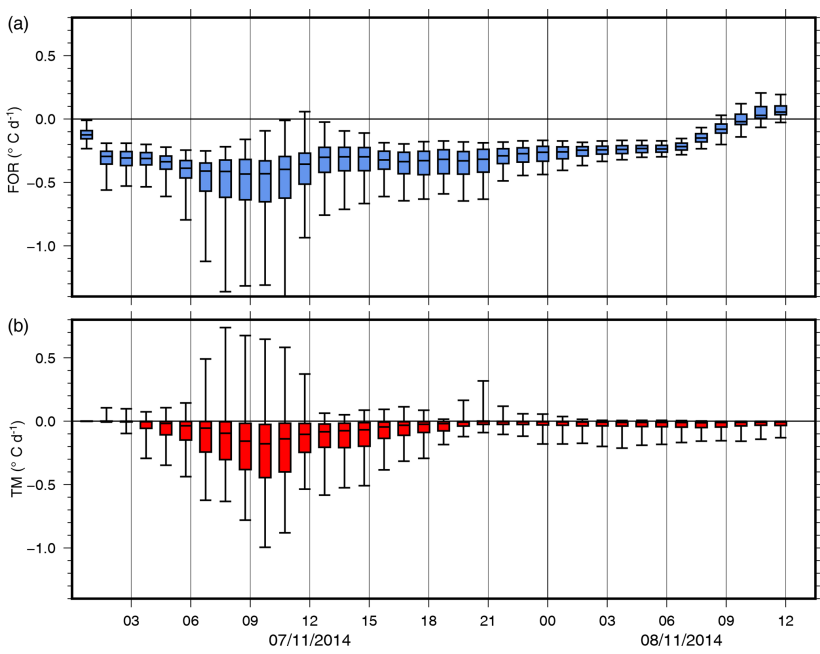

Figure 8. Time series of the median values of the surface forcing (FOR) (a) and turbulent mixing (TM) (b) tendency terms in the evolution of the temperature in the OML and in the SFA. The boxes correspond to the $25 \%$ and $75 \%$ quantiles and the whiskers to the $5 \%$ and $95 \%$ quantiles.

BL by shoaling the mixed layer. During the event, the depth of the thermocline (defined by the depth where $\theta$ is equal to the $10 \mathrm{~m}$ temperature minus $0.3^{\circ} \mathrm{C}$ ) averaged over the SFA oscillates with an amplitude of a few metres (Fig. 10b) due to the near-inertial waves. The freshening due to heavy rain on the morning of 7 November makes the MLD, defined by a density criterion, shallower and governed by salinity rather than temperature. The BL thickness increasing from $5.8 \mathrm{~m}$ at 04:00 UTC to $8.1 \mathrm{~m}$ at 12:00 UTC on 7 November insulates the OML from the colder water below the thermocline.

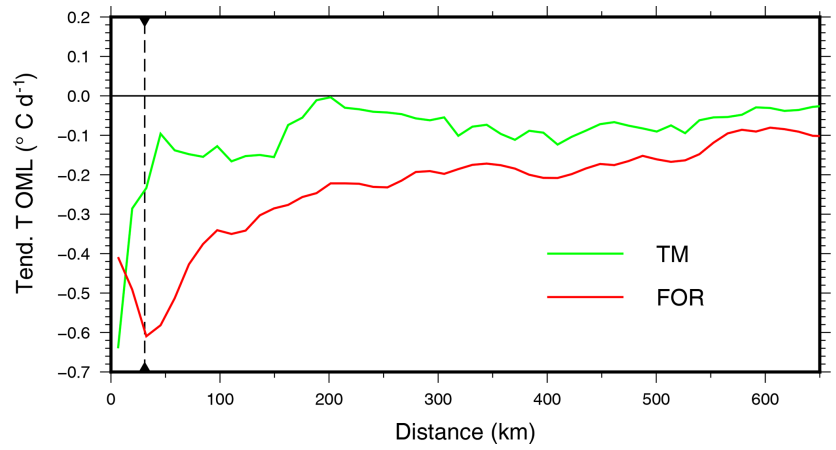

Figure 9. Mean values of the turbulent mixing (green) and surface forcing (red) tendency terms for temperature evolution in the OML at 10:00 UTC on 7 November. The values are radially averaged every $12 \mathrm{~km}$ from the medicane centre. The vertical dashed line indicates the radius of maximum wind.

It enhances the efficiency of the surface heat extraction and reduces the effect of the turbulent mixing.

\section{Role of preconditioning and oceanic evolution}

To quantify the role of oceanic preconditioning and precipitation in the oceanic response to the medicane, we define different zones within the SFA. The EDDY zone is defined as the area of the ABV cyclonic eddy using an SST of $20.5^{\circ} \mathrm{C}$ as a threshold (1005 grid points). We also define a heavy rain zone as the area, in the Strait of Sicily, where integrated water flux at 00:00 UTC on 8 November reaches $90 \mathrm{~mm}$ of water. This heavy rain (HR hereafter) zone includes 2383 grid points, and its mean integrated water flux at 12:00 UTC on 8 November is $136 \mathrm{~mm}$. Note that it is not entirely within 


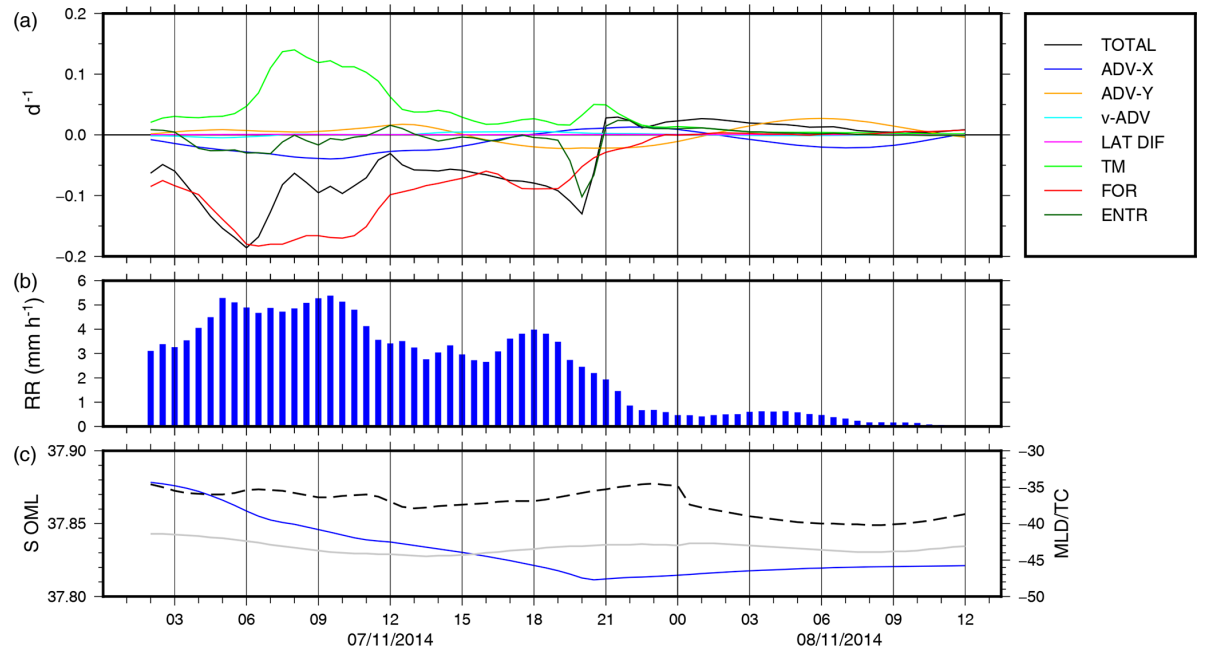

Figure 10. Time series of the different components of the tendency in the evolution of the salinity in the OML and in the SFA (a, colours), of the instantaneous rain rate (b, blue), and of the time evolution of the salinity in the OML, MLD (dashed black), and $T_{-10 \mathrm{~m}}-0.3^{\circ} \mathrm{C}$ thermocline (grey) in the SFA (c).

the SFA (Fig. 6). Finally, a reference zone includes the grid points of the SFA that are not part of either the EDDY or the HR zone (REF hereafter, 4343 grid points). The objective here is to evaluate whether the characteristics of the central Mediterranean (bathymetry, dynamics) or heavy rain control the oceanic response to the event.

\subsection{Effect of the cyclonic eddy}

The time evolution of the SST and OML temperature, in the zones EDDY and REF, is shown in Fig. 11a. The corresponding values at 00:00 UTC on 8 November are given in Table 2 . All along the simulation, the SST and $\langle\theta\rangle$ in both EDDY and REF evolve similarly with a continuous decrease. The OML cooling in EDDY is weaker than in REF $\left(-0.32 \pm 0.25^{\circ} \mathrm{C}\right.$ versus $-0.54 \pm 0.23^{\circ} \mathrm{C}$ at $00: 00 \mathrm{UTC}$ on 8 November) as is the integrated surface heat flux (Fig. 11b). The weaker cooling in EDDY originates from lower heat fluxes throughout the event and especially between 09:00 and 16:00 UTC on 7 November (see also Table 3 for the integrated values of the surface heat flux, WEF, and water flux at 12:00 UTC on 8 November). Lower fluxes result from the difference of SST in the two zones $\left(20.0 \pm 0.4{ }^{\circ} \mathrm{C}\right.$ for EDDY versus $21.6 \pm 0.5^{\circ} \mathrm{C}$ for REF at the beginning of the simulation) but also from the difference in wind speed (median WEF at 10:00 UTC on 7 November $0.11 \mathrm{~kg} \mathrm{~s}^{-3}$ for EDDY versus $0.20 \mathrm{~kg} \mathrm{~s}^{-3}$ for REF). Other differences include a significantly shallower MLD in EDDY ( $16 \mathrm{~m}$ versus $36 \mathrm{~m}$ in REF) and a weaker $100 \mathrm{~m}$ stratification at the beginning of the simulation with an SI of $88 \pm 14 \mathrm{~kg} \mathrm{~m}^{-2}$ versus $125 \pm 12 \mathrm{~kg} \mathrm{~m}^{-2}$ in REF.

The tendency terms for $\langle\theta\rangle$ (Fig. 12 and Table 3) confirm that different surface forcing leads to different cooling in EDDY and REF. In EDDY, the time evolution of FOR

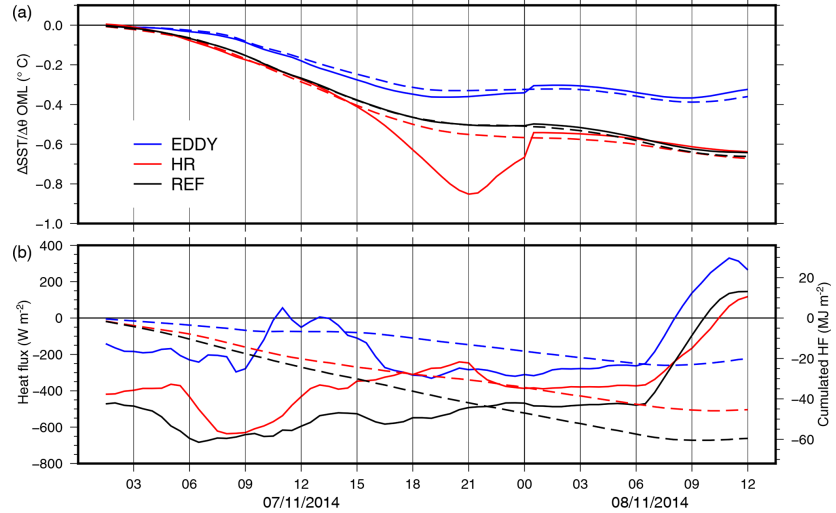

Figure 11. Time series of the SST (solid line) and potential temperature in the OML (dashed line) (a) and instantaneous (solid line, left-hand-side scale) and integrated downward heat flux (dashed line, right-hand-side scale) (b) in the EDDY (blue), HR (red), and REF (black) zones (see text).

mimics the heat flux (red curves in Fig. 12a) with almost no forcing between 10:00 and 14:00 UTC on 7 November. The contribution of TM is stronger than in REF, especially between 08:00 and 14:00 UTC on 7 November. Yet the WEF is much weaker in EDDY than in REF as the integrated value at 12:00 UTC on 8 November represents one-third of it. The stronger mixing in EDDY is due to a weaker stratification and a much shallower $-0.3{ }^{\circ} \mathrm{C}$ thermocline (around $24 \mathrm{~m}$ versus $37 \mathrm{~m}$ in REF). This is consistent with the results of Jullien et al. (2014) showing that in stronger TCs, surface cooling is promoted by cyclonic eddies. Here, the cooling is weaker in EDDY than is REF, but the part of the cooling due to mixing (which is dominant in intense TCs) is larger. The horizontal advection significantly contributes to alternatively cool and 
Table 2. Evolution of oceanic parameters between the beginning of the simulation (04:00 UTC on 7 November) and 00:00 UTC on 8 November in the different zones (see text).

\begin{tabular}{lrrrr}
\hline & SFA & EDDY & HR & REF \\
\hline$\Delta$ SST $\left({ }^{\circ} \mathrm{C}\right)$ & $-0.56 \pm 0.24$ & $-0.34 \pm 0.27$ & $-0.67 \pm 0.23$ & $-0.51 \pm 0.21$ \\
$\Delta\langle\theta\rangle\left({ }^{\circ} \mathrm{C}\right)$ & $-0.54 \pm 0.23$ & $-0.32 \pm 0.25$ & $-0.57 \pm 0.24$ & $-0.51 \pm 0.22$ \\
$\Delta$ SSS & $-0.09 \pm 0.14$ & $0.01 \pm 0.03$ & $-0.24 \pm 0.22$ & $-0.04 \pm 0.07$ \\
$\Delta\langle S\rangle$ & $-0.07 \pm 0.07$ & $0.00 \pm 0.03$ & $-0.12 \pm 0.07$ & $-0.05 \pm 0.07$ \\
$\Delta$ MLD (m) & $1.0 \pm 12.8$ & $8.3 \pm 4.0$ & $-8.9 \pm 13.7$ & $5.1 \pm 9.2$ \\
$\Delta$ BLT (m) & $0.7 \pm 9.6$ & $-4.2 \pm 2.8$ & $7.8 \pm 12.7$ & $-2.4 \pm 4.7$ \\
\hline
\end{tabular}
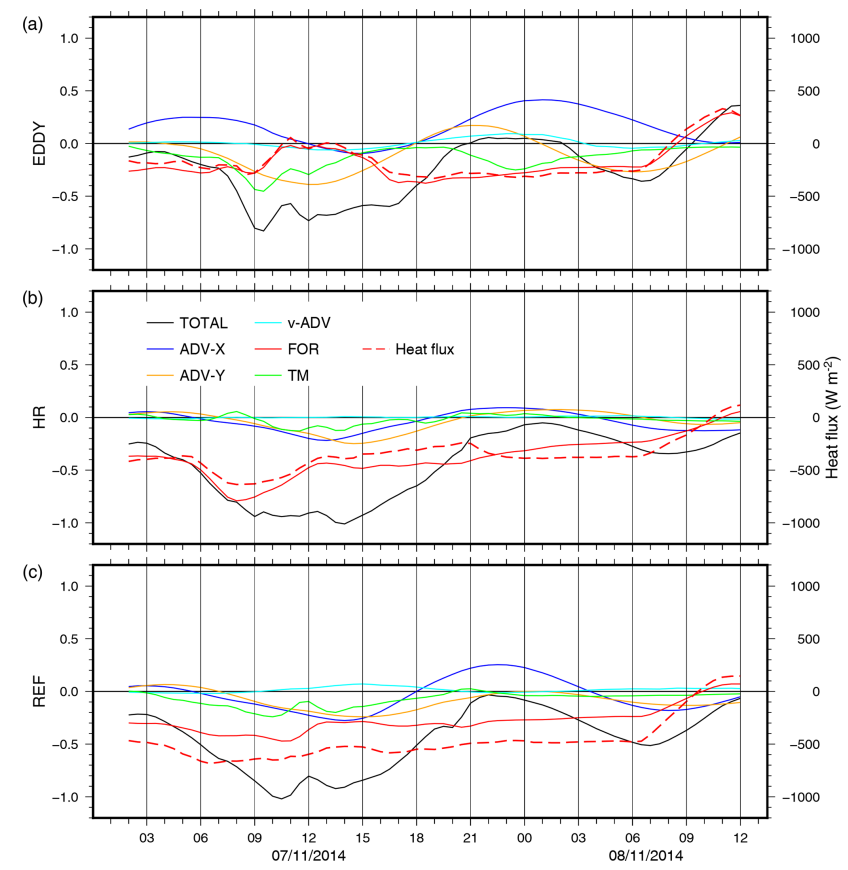

Figure 12. Time series of the different components of the tendency in the evolution of temperature in the OML, in the EDDY (a), HR (b), and REF (c) areas. The net downward heat flux is also shown (dashed red line, right-hand-side scale).

warm the OML (total cooling of $-0.20^{\circ} \mathrm{C}$ by ADV-Y and total warming of $0.23{ }^{\circ} \mathrm{C}$ by $\mathrm{ADV}-\mathrm{X}$ in EDDY). In REF, it cools the OML by -0.12 (ADV-X) and $-0.14^{\circ} \mathrm{C}(\mathrm{ADV}-\mathrm{Y})$ like in the SFA.

Within EDDY, the salinity does not change significantly throughout the simulation (Fig. 13a; Table 2). Except between 09:00 and 11:00 UTC on 7 November, the rainfall amount in REF is low (44\% of the integrated value of the SFA). However, the integrated water flux (dominated by precipitation) is even much lower in EDDY (9.6 versus $27.7 \mathrm{~mm}$ at the end of the simulation; Fig. 13c; Table 3). The tendency terms confirm that precipitation drives the salinity evolution similarly in both zones (Fig. 14a and c) with a largely compensating turbulent mixing (bringing saltier water from under the OML). In both zones, the OML deepens by a few
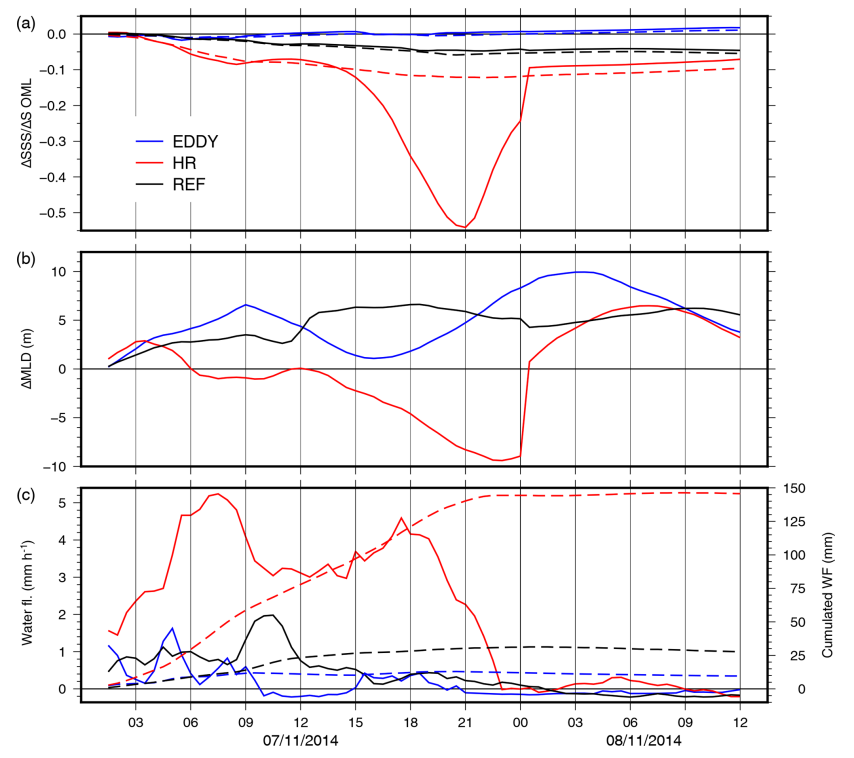

Figure 13. Time series of the SSS (solid line) and mean salinity in the OML (dashed line, a), MLD (b), and instantaneous (solid line, left-hand-side scale) and integrated water flux (dashed line, righthand-side scale) (c) in the EDDY (blue), HR (red), and REF (black) zones (see text).

metres at the beginning of the event due to the cooling effect (Fig. 13b).

Within the ABV eddy, colder SSTs and shallower MLD and thermocline result in less surface cooling. The turbulent mixing intensifies due to the weaker stratification, but the surface forcing is reduced, resulting in less overall cooling. Lateral advection contributes more to the cooling and warming of the OML than outside of the eddy. Low precipitation and moderate mixing bringing more saline water upwards compensate each other and do not noticeably change the OML salinity.

\subsection{Role of heavy precipitation}

We compare here the time evolution of the temperature and salinity in the OML and the corresponding tendency terms in the HR and REF zones. At the beginning of the simulation, the OML is shallower in HR than in REF $(29 \pm 10$ 
Table 3. Integrated forcings and effects of OML tendency terms between the beginning of the simulation (04:00 UTC on 7 November) and 12:00 UTC on 8 November in the different zones (see text). HFL is heat flux, and WFL is water flux.

\begin{tabular}{lrrrr}
\hline & SFA & EDDY & HR & REF \\
\hline HFL $(\mathrm{MJ})$ & $-54.8 \pm 16.1$ & $-20.1 \pm 7.0$ & $-45.3 \pm 11.6$ & $-59.5 \pm 16.4$ \\
WFL $(\mathrm{mm})$ & $63.0 \pm 61.9$ & $9.6 \pm 19.8$ & $136.0 \pm 36.4$ & $27.7 \pm 28.0$ \\
WEF $\left(10^{3} \mathrm{~kg} \mathrm{~s}^{-2}\right)$ & $15.3 \pm 6.1$ & $4.7 \pm 3.6$ & $16.2 \pm 7.0$ & $14.3 \pm 6.2$ \\
INT FOR $T\left({ }^{\circ} \mathrm{C}\right)$ & $-0.45 \pm 0.12$ & $-0.26 \pm 0.08$ & $-0.55 \pm 0.11$ & $-0.40 \pm 0.09$ \\
INT TM $T\left({ }^{\circ} \mathrm{C}\right)$ & $-0.09 \pm 0.13$ & $-0.19 \pm 0.06$ & $-0.03 \pm 0.14$ & $-0.11 \pm 0.12$ \\
INT ADV-X T $\left({ }^{\circ} \mathrm{C}\right)$ & $-0.06 \pm 0.22$ & $0.22 \pm 0.31$ & $-0.06 \pm 0.21$ & $-0.05 \pm 0.22$ \\
INT ADV-Y T $\left({ }^{\circ} \mathrm{C}\right)$ & $-0.11 \pm 0.26$ & $-0.16 \pm 0.20$ & $-0.06 \pm 0.27$ & $-0.12 \pm 0.25$ \\
INT FOR $S$ & $-0.09 \pm 0.10$ & $-0.02 \pm 0.04$ & $-0.21 \pm 0.10$ & $-0.04 \pm 0.05$ \\
INT TM $S$ & $0.05 \pm 0.07$ & $0.02 \pm 0.03$ & $0.11 \pm 0.08$ & $0.02 \pm 0.04$ \\
INT ADV-X $S$ & $-0.02 \pm 0.07$ & $0.01 \pm 0.02$ & $-0.01 \pm 0.07$ & $-0.03 \pm 0.08$ \\
INT ADV-Y $S$ & $0.00 \pm 0.07$ & $0.01 \pm 0.03$ & $0.01 \pm 0.07$ & $0.00 \pm 0.07$ \\
\hline
\end{tabular}

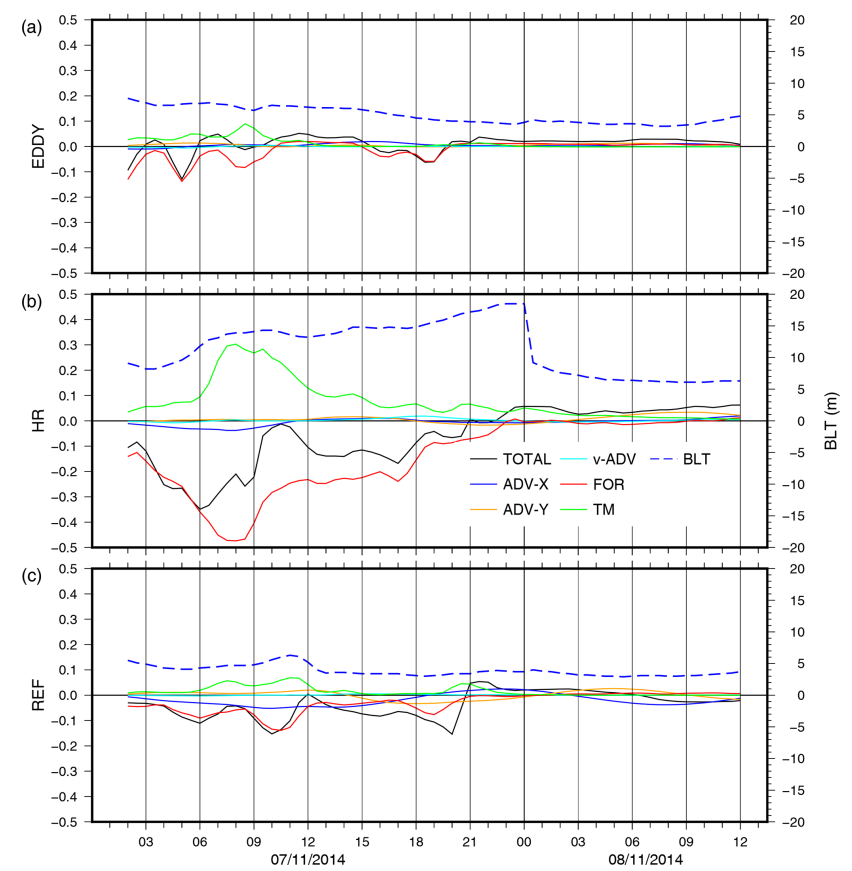

Figure 14. Time series of the different components of the tendency in the evolution of salinity in the OML, in the EDDY (a), HR (b), and reference (c) areas. The barrier layer thickness (BLT) is also shown (dashed blue line, right-hand-side scale).

versus $36 \pm 11 \mathrm{~m}$ ) with SI at $100 \mathrm{~m}$ around $125 \mathrm{~kg} \mathrm{~m}^{-2}$ in both cases. The SST is also similar $\left(\sim 21.5 \pm 0.5^{\circ} \mathrm{C}\right)$, and the surface water is slightly fresher in $\operatorname{HR}(37.61 \pm 0.12$ versus $37.73 \pm 0.17)$. Comparing the temperature, salinity, and density anomaly vertical profiles (not shown here) gives stronger gradients of temperature and salinity between the surface and $60 \mathrm{~m}$ in HR than in REF but results in similar density profiles in both zones. The time evolution of $\langle\theta\rangle$ is rather similar with respective coolings at 00:00 UTC on 8 November of -0.57 and $-0.51^{\circ} \mathrm{C}$ (Fig. 11a; Table 2). Yet the integrated heat loss in HR is $31 \%$ higher in REF than in HR (Fig. 11b; Table 3).
Thus, the surface forcing is much more efficient in cooling the OML in HR than in REF (Fig. 12b and c). Looking at the tendency terms shows that FOR is stronger in HR than in REF but that TM is stronger in REF than in HR (Table 3). These discrepancies in the cooling effects in HR and REF can be related to the impact of the precipitation on the upperocean salinity and the resulting MLD variations. In HR, the heavy rain on the morning of 7 November produces the first drop of the SSS of -0.1 (Fig. 13a) and shoals the OML by a few metres (Fig. 13b). This may be enhanced by the strong pre-existing salinity gradient. As a result, the shallower OML is more sensitive to the atmospheric forcing and is insulated from the colder waters below the thermocline by a $13 \mathrm{~m}$ thick BL (Fig. 14b). As was shown for TCs, the effect of the surface heat fluxes on the SST is enhanced, while the turbulent mixing is dampened (Yan et al., 2017). Indeed, TM starts to decrease at 10:00 UTC in HR while the WEF increases until 12:00 UTC on 7 November. The net result here is a stronger cooling since the FOR term is dominant because of the weak intensity of the event. After this first freshening and cooling of the OML due to the heavy rain on the morning of 7 November, lighter rain occurs in the afternoon. Yet, because the thinned OML is very sensitive to the atmospheric forcing at that time, this leads to strong additional freshening ( -0.5 in total) and shoaling of the OML (Fig. 13). The water flux controlling the MLD explains the stronger cooling in HR with an SST cooling of $0.8^{\circ} \mathrm{C}$ at 21:00 UTC on 7 November (Fig. 11).

These results are consistent with the role of BLs (usually pre-existent) in modulating the surface cooling due to TCs. In weak TCs where the cooling effect is mainly due to the surface heat fluxes, the presence of BLs makes the OML shallower and enhances the surface forcing (Hlywiak and Nolan, 2019). Its isolating effect from colder water below the thermocline does not impact much the cooling since turbulent mixing is a secondary mechanism. The novel result here is that the BL formation and deepening arise from heavy precipitation occurring at the beginning of the event. A realis- 
tic study of the net effect of precipitation versus evaporation and mixing on the surface salinity in TC wakes showed that the BL thickness increases in every cyclonic basin (Steffen and Bourassa, 2018). It is not clear, however, whether this overall freshening happens early enough during the TC development to substantially impact the cooling. Here, because of the deep convective rainfall in the first phase of the event $\left(11 \mathrm{~mm} \mathrm{~h}^{-1}\right.$ on average during the first $\left.10 \mathrm{~h}\right)$, a BL rapidly forms and strengthens the cooling effect of surface fluxes.

\section{Discussion and conclusion}

Comparing a medicane with low-intensity TCs from the viewpoint of the upper-layer oceanic processes proves to be relevant and reveals many similarities and a few differences. According to its maximum sustained wind, the medicane studied here is comparable to TCs of Category 1 on the Saffir-Simpson scale. Its duration is nevertheless much shorter than a typical TC with wind energy flux above $0.2 \mathrm{~kg} \mathrm{~s}^{-3}$ for a few hours only between 07:00 and 13:00 UTC on 7 November and upward heat fluxes above $400 \mathrm{~W} \mathrm{~m}^{-2}$ for $30 \mathrm{~h}$ between the beginning of the event and 07:00 UTC on 8 November. The mean surface cooling on the SFA is therefore less than $-0.6^{\circ} \mathrm{C}$, which is significantly lower than the typical cooling of weak TCs. The dominant cooling mechanism is the surface forcing (at the origin of a $-0.45^{\circ} \mathrm{C}$ cooling), while the turbulent mixing accounts for less than $-0.1^{\circ} \mathrm{C}$. These two mechanisms do not act simultaneously: the surface forcing starts earlier, peaks at 09:00 UTC on 7 November, and stays above $-400 \mathrm{~W} \mathrm{~m}^{-2}$ for more than $24 \mathrm{~h}$ in total; the turbulent mixing increases until 12:00 UTC on 7 November and drops rapidly in the afternoon of 7 November. This may show that surface forcing has a much larger effect than turbulent mixing on the OML temperature. Yet the cooling effect of the surface fluxes is at the upper threshold of the typical range given by Vincent et al. (2012a), while the cooling effect of the turbulent mixing is always weak even at the peak intensity of the event. This discrepancy can be explained by the effect of heavy rainfall in the first hours of the event, which create or deepen an existing BL. Indeed, comparing the cooling of two areas forced by similar wind stress and heat fluxes but very different water fluxes show that the presence of the BL results in a $37 \%$ increase in the effect of the surface forcing and $64 \%$ decrease in the effect of the turbulent mixing.

A diagram based on the simulated mean profiles and MLD values summarizes the upper-layer evolution throughout the event and the impact of heavy rain (Fig. 15). Before the event, both REF and HR zones have similar profiles in temperature and salinity (dotted black lines, Fig. 15a and b), with an MLD of $37 \mathrm{~m}$ controlled by temperature. During the first part of the event, the temperature evolution is the same in REF and HR and is mainly due to the surface heat extraction (Fig. 15a, dashed line). The salinity decrease in the OML is mainly due to the rain-evaporation balance at the surface and is larger in HR close to the surface (Fig. 15b, blue versus black dashed lines). As a result, the MLD is governed by temperature in REF and increases to $42 \mathrm{~m}$ (dashed black line, Fig. 15c), while it is controlled by salinity in HR and slightly decreases to $36 \mathrm{~m}$ (dashed blue line, Fig. 15c). During the second part of the event, the temperature and salinity evolutions in REF are very similar to those of the first part except that mixing close to the OML bottom and horizontal advection result in a stronger cooling between 25 and $50 \mathrm{~m}$ (solid black lines, Fig. 15a). In HR conversely, the slightly thinner OML due to the surface freshening which occurred during the first part of the event makes the OML more sensitive to surface forcing. The effect of precipitation on salinity is amplified with a strong decrease at the surface (solid blue line, Fig. 15b), and this salinity change controls the change in density with a corresponding decrease at the surface and large shoaling of the MLD to $22 \mathrm{~m}$ (solid blue line, Fig. 15c). Heavy precipitation also acts on the surface temperature during the second half of the event (Fig. 15a; see also Fig. 11) even though it had been occurring since the beginning of the event. This delayed effect is due to the positive feedback of a salinity-induced thinning of the OML, which settles after a few hours only. Heavy convective precipitation is usual during the development phase of medicanes before the wind reaches its maximum speed, and the preconditioning effect of the oceanic upper layer we obtain here is probably rather typical. Mediterranean cyclones in general come with heavy rain, which are prone to alter the response of the oceanic upper layer as observed here. On the OML salinity, the effects of both the surface forcing and the turbulent mixing are enhanced by the BL.

Lateral advection plays a secondary but significant role in cooling or warming the OML. In particular, strong upperlayer horizontal currents develop close to the cyclone centre in the ABV eddy. Colder water is shifted southwards, reinforcing the cooling, and warmer water is brought towards the eddy centre by converging motions from the surrounding area with deeper OML. In addition, due to shallower MLD and weaker $100 \mathrm{~m}$ stratification in the eddy, the effect of the surface heat fluxes is lower, while the effect of the turbulent mixing is strengthened. As a result, the cooling in the ABV eddy is dampened with respect to the surroundings. The peculiar dynamics of the Strait of Sicily, with its strong currents and the regular presence of eddies, is able to modulate the impact of cyclones on the ocean.

The present study is in strong contrast with the case study of a strong storm with comparable sustained wind speed in the north-western Mediterranean (Renault et al., 2012). The cooling obtained by these authors was between -1.5 and $-2{ }^{\circ} \mathrm{C}$ over the large area of the Gulf of Lion. A precise comparison of the two events and of their impact on the oceanic upper layer is beyond the scope of the present study, but several factors can partly explain the stronger cooling they obtained. First, the duration of the storm was longer than 


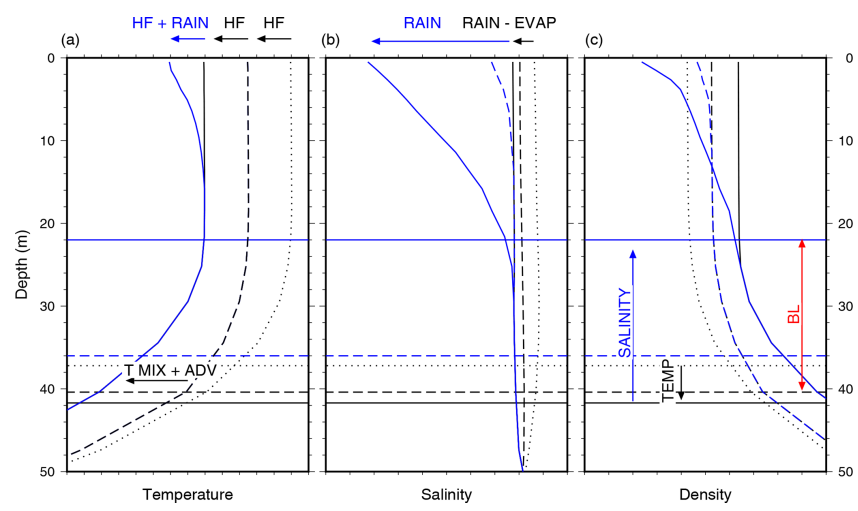

Figure 15. Diagram of the upper-layer evolution in temperature (a), salinity (b), and density (c) in the REF (black) and HR (blue, when it differs from REF) zones. The profiles of parameters are indicated at the beginning (dotted), middle (dashed), and end (solid) of the event. The horizontal lines indicate the MLD in the REF (black) and HR (blue) zones at the beginning (dotted), middle (dashed), and end (solid) of the simulation. The horizontal arrows indicate the processes at the origin of the profile changes: surface heat fluxes (HF), rain forcing (RAIN), evaporation (EVAP), turbulent mixing ( $T$ MIX), and horizontal advection (ADV) in black for the REF zone and blue for the HR zone. The vertical arrows in (c) indicate the parameters controlling the changes in MLD in the REF (black) and HR (blue) zones. The red arrow indicates the BL in the HR zone.

Qendresa with strong wind stress and heat fluxes from 4 until 6 May. The track of the storm was also favourable to a stronger impact on the ocean since it looped for $3 \mathrm{~d}$ over the Gulf of Lion. Second, the MLD in May in the Gulf of Lion is usually shallower than in November in the Strait of Sicily with values in the range of $10-30 \mathrm{~m}$ (d'Ortenzio et al., 2005). More precisely, observations of the Lion buoy show that prior to the storm, the temperature at $10 \mathrm{~m}$ was $-0.3{ }^{\circ} \mathrm{C}$ below the SST (taken at $2 \mathrm{~m}$; see Houpert et al., 2016). No measurements were available at that time at depths between 10 and $200 \mathrm{~m}$, but observations on the same date in 2012 show a $-0.6^{\circ} \mathrm{C}$ difference between the temperature at $15 \mathrm{~m}$ and the SST and $\mathrm{a}-1{ }^{\circ} \mathrm{C}$ difference at $35 \mathrm{~m}$. The upper layer was thus likely strongly stratified before the storm, and this favours the cooling by turbulent mixing. As far as we can judge, atmospheric and oceanic conditions acted together to enhance the impact of the turbulent mixing, and this resulted in a stronger cooling.

This study is based on a single case, and our results should be confirmed by simulating more events. A broader study involving a statistically significant number of Mediterranean cyclones is nevertheless still challenging. Intense cyclones like the present case occur one to two times per year (e.g. Cavicchia et al., 2014), and our results show that highresolution oceanic models are necessary to represent the finescale features modulating the oceanic response. The atmospheric forcing should also be well resolved to realistically reproduce the intensity and variations of the surface input. The simple comparison with the oceanic impacts obtained by Renault et al. (2012) shows that Mediterranean storms are diverse and, depending on the area and season concerned, can lead to different oceanic responses due to the different processes. Previous studies at the climatological scale show that the Strait of Sicily is among the preferred areas for medicane formation (Cavicchia et al., 2014). The processes exposed here, especially the time lag between intense rainfall occurring at the beginning of the event and maximum intensity of heat and wind stress, are characteristic of medicanes (Miglietta et al., 2013). We are thus convinced that the enhanced effect of the surface forcing and the reduced effect of the turbulent mixing due to the rain-induced barrier layer are rather widespread under medicanes. The ABV eddy, which significantly reduces the cooling due to colder SSTs and shallower MLD, is not always present. Yet both cyclonic and anticyclonic structures are common in the central Mediterranean and able to modulate, as was shown here, the oceanic response to medicanes.

Code and data availability. The source codes are available online: Meso-NH (http://mesonh.aero.obs-mip.fr/mesonh54, French research community, 2020) and NEMO (https: //www.nemo-ocean.eu/, NEMO Consortium, 2020). The PSY2V4R4 daily analyses are available on the Copernicus Marine Environment Monitoring Service portal (http://marine.copernicus.eu, Copernicus, 2020). The GHRSST satellite SST data can be obtained upon registration from the Centre de Recherche et d'Exploitation Satellitaire (CERSAT), Ifremer (http://cersat.ifremer.fr/thematic-portals/projects/medspiration/ access-to-data-and-services, last access: 18 September 2020).

Author contributions. MNB and CLB designed the study and set up the numerical configuration. MNB performed the simulation. MNB and CLB analysed the results and wrote the paper.

Competing interests. The authors declare that they have no conflict of interest.

Special issue statement. This article is part of the special issue "Hydrological cycle in the Mediterranean (ACP/AMT/GMD/HESS/NHESS/OS inter-journal SI)". It is not associated with a conference.

Acknowledgements. This work is a contribution to the HyMeX programme (Hydrological cycle in the Mediterranean EXperiment; http://www.hymex.org, last access: 18 September 2020) through INSU-MISTRALS support. The authors acknowledge the Pôle de Calcul et de Données Marines for the DATARMOR facilities (storage, data access, computational resources). The PSY2V4R4 daily analyses were made available by the Copernicus Marine Envi- 
ronment Monitoring Service (http://marine.copernicus.eu, last access: 18 September 2020). The GHRSST satellite SST data were obtained from the Centre de Recherche et d'Exploitation Satellitaire (CERSAT) at Ifremer, Plouzane (France), on behalf of the ESA/Medspiration project. The authors thank Swen Jullien for valuable discussions. We are also grateful to James Hlywiak and Ali Harzallah who helped by their reviews to improve this paper.

Review statement. This paper was edited by Katrin Schroeder and reviewed by James Hlywiak and Ali Harzallah.

\section{References}

Arsouze, T., Beuvier, J., Béranger, K., Somot, S., Brossier, C. L., Bourdallé-Badie, R., and Drillet, Y.: Sensibility analysis of the Western Mediterranean Transition inferred by four companion simulations, CIESM, Marseille, France, Vol. 27, 2013.

Barnier, B., Madec, G., Penduff, T., Molines, J.-M., Treguier, A.M., Le Sommer, J., Beckmann, A., Biastoch, A., Böning, C., Dengg, J., et al.: Impact of partial steps and momentum advection schemes in a global ocean circulation model at eddy-permitting resolution, Ocean Dynam., 56, 543-567, 2006.

Béjaoui, B., Ben Ismail, S., Othmani, A., Ben Abdallah-Ben Hadj Hamida, O., Chevalier, C., Feki-Sahnoun, W., Harzallah, A., Ben Hadj Hamida, N., Bouaziz, R., Dahech, S., Diaz, F., Tounsi, K., Sammari, C., Pagano, M., and Bel Hassen, M.: Synthesis review of the Gulf of Gabes (eastern Mediterranean Sea, Tunisia): Morphological, climatic, physical oceanographic, biogeochemical and fisheries features, Estuar. Coast. Shelf S., 219, 395-408, 2019.

Belamari, S.: Report on uncertainty estimates of an optimal bulk formulation for surface turbulent fluxes, Marine EnviRonment and Security for the European Area-Integrated Project (MERSEA IP), Deliverable D, Vol. 4, 2005.

Belamari, S. and Pirani, A.: Validation of the optimal heat and momentum fluxes using the ORCA2-LIM global ocean-ice model, Marine EnviRonment and Security for the European AreaIntegrated Project (MERSEA IP), Deliverable D, Vol. 4, 2007.

Bender, M. A., Ginis, I., and Kurihara, Y.: Numerical simulations of tropical cyclone-ocean interaction with a high-resolution coupled model, J. Geophys. Res.-Atmos., 98, 23245-23263, 1993.

Ben Ismail, S., Chevalier, C., Atoui, A., Devenon, J. L., Sammari, C., and Pagano, M.: Water Masses Exchanges Within Boughrara Lagoon-Gulf of Gabes System (Southeastern Tunisia), in: Recent Advances in Environmental Science from the EuroMediterranean and Surrounding Regions, edited by: Kallel, A., Ksibi, M., Ben Dhia, H., Khe'lifi, N., EMCEI 2017. Advances in Science, Technology \& Innovation (IEREK Interdisciplinary Series for Sustainable Development), Springer, Cham, https://doi.org/10.1007/978-3-319-70548-4_461, 2017.

Beuvier, J., Béranger, K., Lebeaupin Brossier, C., Somot, S., Sevault, F., Drillet, Y., Bourdallé-Badie, R., Ferry, N., and Lyard, F.: Spreading of the Western Mediterranean Deep Water after winter 2005: Time scales and deep cyclone transport, J. Geophys. Res.Oceans, 117, C07022, https://doi.org/10.1029/2011JC007679, 2012.
Blanke, B. and Delecluse, P.: Variability of the tropical Atlantic Ocean simulated by a general circulation model with two different mixed-layer physics, J. Phys. Oceanogr., 23, 1363-1388, 1993.

Bouin, M.-N. and Lebeaupin Brossier, C.: Surface processes in the 7 November 2014 medicane from air-sea coupled highresolution numerical modelling, Atmos. Chem. Phys., 20, 68616881, https://doi.org/10.5194/acp-20-6861-2020, 2020.

Carrió, D., Homar, V., Jansa, A., Romero, R., and Picornell, M.: Tropicalization process of the 7 November 2014 Mediterranean cyclone: Numerical sensitivity study, Atmos. Res., 197, 300312, 2017.

Cavicchia, L., von Storch, H., and Gualdi, S.: A long-term climatology of medicanes, Clim. Dynam., 43, 1183-1195, 2014.

Chen, S., Campbell, T. J., Jin, H., Gaberšek, S., Hodur, R. M., and Martin, P.: Effect of two-way air-sea coupling in high and low wind speed regimes, Mon. Weather Rev., 138, 3579-3602, 2010.

Chiang, T.-L., Wu, C.-R., and Oey, L.-Y.: Typhoon Kai-Tak: An ocean's perfect storm, J. Phys. Oceanogr., 41, 221-233, 2011.

Ciappa, A. C.: Surface circulation patterns in the Sicily Channel and Ionian Sea as revealed by MODIS chlorophyll images from 2003 to 2007, Cont. Shelf Res., 29, 2099-2109, 2009.

Cione, J. J., Black, P. G., and Houston, S. H.: Surface observations in the hurricane environment, Mon. Weather Rev., 128, 15501561, 2000.

Cioni, G., Cerrai, D., and Klocke, D.: Investigating the predictability of a Mediterranean tropical-like cyclone using a stormresolving model, Q. J. Roy. Meteor. Soc., 144, 1598-1610, 2018.

Copernicus: Marine Environment Monitoring Service portal, available at: http://marine.copernicus.eu, last access: 18 September 2020 .

D'Asaro, E. A.: The ocean boundary layer below Hurricane Dennis, J. Phys. Oceanogr., 33, 561-579, 2003.

D’Asaro, E. A., Sanford, T. B., Niiler, P. P., and Terrill, E. J.: Cold wake of hurricane Frances, Geophys. Res. Lett., 34, L15609, https://doi.org/10.1029/2007GL030160, 2007.

d'Ortenzio, F., Iudicone, D., de Boyer Montegut, C., Testor, P., Antoine, D., Marullo, S., Santoleri, R., and Madec, G.: Seasonal variability of the mixed layer depth in the Mediterranean Sea as derived from in situ profiles, Geophys. Res. Lett., 32, L12605, https://doi.org/10.1029/2005GL022463, 2005.

Drago, A., Sorgente, R., and Olita, A.: Sea temperature, salinity and total velocity climatological fields for the south-central Mediterranean Sea, Gcp/Rer/010/Ita/Msm-Td-14, MedSudMed Technical Documents, 35 pp., 2010.

Estournel, C., Testor, P., Damien, P., d'Ortenzio, F., Marsaleix, P., Conan, P., Kessouri, F., Durrieu de Madron, X., Coppola, L., Lellouche, J.-M., Belamari, S., Mortier, L., Ulses, C., Bouin, M.-N., and Prieur, L.: High resolution modeling of dense water formation in the north-western Mediterranean during winter 2012-2013: Processes and budget, J. Geophys. Res.-Oceans, 121, 5367-5392, 2016.

French research community (Laboratoire d'Aérologie and CNRM): Meso NH-5.4, available at: http://mesonh.aero.obs-mip.fr/ mesonh54, last access: 18 September 2020.

Giordani, H., Caniaux, G., and Voldoire, A.: Intraseasonal mixedlayer heat budget in the equatorial Atlantic during the cold tongue development in 2006, J. Geophys. Res.-Oceans, 118, 650-671, 2013. 
Godfrey, J. and Lindstrom, E.: The heat budget of the equatorial western Pacific surface mixed layer, J. Geophys. Res.-Oceans, 94, 8007-8017, 1989.

Greatbatch, R. J.: On the response of the ocean to a moving storm: The nonlinear dynamics, J. Phys. Oceanogr., 13, 357-367, 1983.

Hamad, N., Millot, C., and Taupier-Letage, I.: The surface circulation in the eastern basin of the Mediterranean Sea, Sci. Mar., 70, 457-503, 2006.

Hlywiak, J. and Nolan, D. S.: The Influence of Oceanic Barrier Layers on Tropical Cyclone Intensity as Determined through Idealized, Coupled Numerical Simulations, J. Phys. Oceanogr., 49, 1723-1745, 2019.

Houpert, L., Durrieu de Madron, X., Testor, P., Bosse, A., d'Ortenzio, F., Bouin, M.-N., Dausse, D., Le Goff, H., Kunesch, S., Labaste, M., Coppola, L., Mortier, L., and Raimbault, P.: Observations of open-ocean deep convection in the northwestern M editerranean Sea: Seasonal and interannual variability of mixing and deep water masses for the 2007-2013 Period, J. Geophys. Res.-Oceans, 121, 8139-8171, 2016.

Huang, P., Sanford, T. B., and Imberger, J.: Heat and turbulent kinetic energy budgets for surface layer cooling induced by the passage of Hurricane Frances (2004), J. Geophys. Res.-Oceans, 114, C12023, https://doi.org/10.1029/2009JC005603, 2009.

Jourdain, N. C., Lengaigne, M., Vialard, J., Madec, G., Menkes, C. E., Vincent, E. M., Jullien, S., and Barnier, B.: Observationbased estimates of surface cooling inhibition by heavy rainfall under tropical cyclones, J. Phys. Oceanogr., 43, 205-221, 2013.

Jullien, S., Marchesiello, P., Menkes, C. E., Lefèvre, J., Jourdain, N. C., Samson, G., and Lengaigne, M.: Ocean feedback to tropical cyclones: climatology and processes, Clim. Dynam., 43, 2831-2854, 2014.

Kobashi, F., Doi, H., and Iwasaka, N.: Sea surface cooling induced by extratropical cyclones in the subtropical North Pacific: Mechanism and interannual variability, J. Geophys. Res.-Oceans, 124, 2179-2195, 2019.

Kowaleski, A. M. and Evans, J. L.: Thermodynamic observations and flux calculations of the tropical cyclone surface layer within the context of potential intensity, Weather Forecast., 30, 1303 1320, 2015.

Lac, C., Chaboureau, J.-P., Masson, V., Pinty, J.-P., Tulet, P., Escobar, J., Leriche, M., Barthe, C., Aouizerats, B., Augros, C., Aumond, P., Auguste, F., Bechtold, P., Berthet, S., Bielli, S., Bosseur, F., Caumont, O., Cohard, J.-M., Colin, J., Couvreux, F., Cuxart, J., Delautier, G., Dauhut, T., Ducrocq, V., Filippi, J.B., Gazen, D., Geoffroy, O., Gheusi, F., Honnert, R., Lafore, J.-P., Lebeaupin Brossier, C., Libois, Q., Lunet, T., Mari, C., Maric, T., Mascart, P., Mogé, M., Molinié, G., Nuissier, O., Pantillon, F., Peyrillé, P., Pergaud, J., Perraud, E., Pianezze, J., Redelsperger, J.-L., Ricard, D., Richard, E., Riette, S., Rodier, Q., Schoetter, R., Seyfried, L., Stein, J., Suhre, K., Taufour, M., Thouron, O., Turner, S., Verrelle, A., Vié, B., Visentin, F., Vionnet, V., and Wautelet, P.: Overview of the Meso-NH model version 5.4 and its applications, Geosci. Model Dev., 11, 19291969, https://doi.org/10.5194/gmd-11-1929-2018, 2018.

Lazar, A., Madec, G., and Delecluse, P.: The deep interior downwelling, the Veronis effect, and mesoscale tracer transport parameterizations in an OGCM, J. Phys. Oceanogr., 29, 29452961, 1999.
Lebeaupin Brossier, C., Drobinski, P., Béranger, K., Bastin, S., and Orain, F.: Ocean memory effect on the dynamics of coastal heavy precipitation preceded by a mistral event in the northwestern Mediterranean, Q. J. Roy. Meteor. Soc., 139, 1583-1597, 2013.

Lebeaupin Brossier, C., Arsouze, T., Béranger, K., Bouin, M.-N., Bresson, E., Ducrocq, V., Giordani, H., Nuret, M., Rainaud, R., and Taupier-Letage, I.: Ocean Mixed Layer responses to intense meteorological events during HyMeX-SOP1 from a highresolution ocean simulation, Ocean Model., 84, 84-103, 2014.

Leipper, D. F.: Observed ocean conditions and Hurricane Hilda, 1964, J. Atmos. Sci., 24, 182-186, 1967.

Leipper, D. F. and Volgenau, D.: Hurricane heat potential of the Gulf of Mexico, J. Phys. Oceanogr., 2, 218-224, 1972.

Lellouche, J.-M., Le Galloudec, O., Drévillon, M., Régnier, C., Greiner, E., Garric, G., Ferry, N., Desportes, C., Testut, C.-E., Bricaud, C., Bourdallé-Badie, R., Tranchant, B., Benkiran, M., Drillet, Y., Daudin, A., and De Nicola, C.: Evaluation of global monitoring and forecasting systems at Mercator Océan, Ocean Sci., 9, 57-81, https://doi.org/10.5194/os-9-57-2013, 2013.

Lin, I., Wu, C.-C., Emanuel, K. A., Lee, I.-H., Wu, C.-R., and Pun, I.-F.: The interaction of Supertyphoon Maemi (2003) with a warm ocean eddy, Mon. Weather Rev., 133, 2635-2649, 2005.

Lin, I., Wu, C.-C., Pun, I.-F., and Ko, D.-S.: Upper-ocean thermal structure and the western North Pacific category 5 typhoons. Part I: Ocean features and the category 5 typhoons' intensification, Mon. Weather Rev., 136, 3288-3306, 2008.

Lloyd, I. D. and Vecchi, G. A.: Observational evidence for oceanic controls on hurricane intensity, J. Climate, 24, 1138-1153, 2011.

Lonfat, M., Marks Jr., F. D., and Chen, S. S.: Precipitation distribution in tropical cyclones using the Tropical Rainfall Measuring Mission (TRMM) microwave imager: A global perspective, Mon. Weather Rev., 132, 1645-1660, 2004.

Lyard, F., Lefevre, F., Letellier, T., and Francis, O.: Modelling the global ocean tides: modern insights from FES2004, Ocean Dynam., 56, 394-415, 2006.

Madec, G. and Imbard, M.: A global ocean mesh to overcome the North Pole singularity, Clim. Dynam., 12, 381-388, 1996.

Madec, G. and the NEMO team: NEMO ocean engine, Note du Pôle de modélisation de l'Institut Pierre-Simon Laplace No. 27, ISSN No 1288-1619, 2015.

Masson, V., Le Moigne, P., Martin, E., Faroux, S., Alias, A., Alkama, R., Belamari, S., Barbu, A., Boone, A., Bouyssel, F., Brousseau, P., Brun, E., Calvet, J.-C., Carrer, D., Decharme, B., Delire, C., Donier, S., Essaouini, K., Gibelin, A.-L., Giordani, H., Habets, F., Jidane, M., Kerdraon, G., Kourzeneva, E., Lafaysse, M., Lafont, S., Lebeaupin Brossier, C., Lemonsu, A., Mahfouf, J.-F., Marguinaud, P., Mokhtari, M., Morin, S., Pigeon, G., Salgado, R., Seity, Y., Taillefer, F., Tanguy, G., Tulet, P., Vincendon, B., Vionnet, V., and Voldoire, A.: The SURFEXv7.2 land and ocean surface platform for coupled or offline simulation of earth surface variables and fluxes, Geosci. Model Dev., 6, 929-960, https://doi.org/10.5194/gmd-6-929-2013, 2013.

Mei, W. and Pasquero, C.: Spatial and temporal characterization of sea surface temperature response to tropical cyclones, J. Climate, 26, 3745-3765, 2013.

Miglietta, M., Laviola, S., Malvaldi, A., Conte, D., Levizzani, V., and Price, C.: Analysis of tropical-like cyclones over the Mediterranean Sea through a combined modeling and satellite approach, Geophys. Res. Lett., 40, 2400-2405, 2013. 
Morcrette, J.-J.: Radiation and cloud radiative properties in the ECMWF operational weather forecast model, J. Geophys. Res., 96, 9121-9132, 1991.

Morey, S. L., Bourassa, M. A., Dukhovskoy, D. S., and O’Brien, J. J.: Modeling studies of the upper ocean response to a tropical cyclone, Ocean Dynam., 56, 594-606, 2006.

NEMO Consortium: NEMO, available at: https://www. nemo-ocean.eu/, last access: 18 September 2020.

Omrani, H., Arsouze, T., Béranger, K., Boukthir, M., Drobinski, P., Lebeaupin-Brossier, C., and Mairech, H.: Sensitivity of the sea circulation to the atmospheric forcing in the Sicily Channel, Prog. Oceanogr., 140, 54-68, 2016.

Piolle, J.-F., Autret, E., Arino, O., Robinson, I. S., and Le Borgne, P.: Medspiration: toward the sustained delivery of satellite SST products and services over regional seas, ESASP, 686, p. 361, 2010.

Poulain, P.-M. and Zambianchi, E.: Surface circulation in the central Mediterranean Sea as deduced from Lagrangian drifters in the 1990s, Cont. Shelf Res., 27, 981-1001, 2007.

Price, J. F.: Upper ocean response to a hurricane, J. Phys. Oceanogr., $11,153-175,1981$.

Pytharoulis, I.: Analysis of a Mediterranean tropical-like cyclone and its sensitivity to the sea surface temperatures, Atmos. Res., 208, 167-179, 2018.

Rainaud, R., Lebeaupin Brossier, C., Ducrocq, V., and Giordani, H.: High-resolution air-sea coupling impact on two heavy precipitation events in the Western Mediterranean, Q. J. Roy. Meteor. Soc., 143, 2448-2462, 2017.

Ren, X., Perrie, W., Long, Z., and Gyakum, J.: Atmosphere-ocean coupled dynamics of cyclones in the midlatitudes, Mon. Weather Rev., 132, 2432-2451, 2004.

Renault, L., Chiggiato, J., Warner, J. C., Gomez, M., Vizoso, G., and Tintoré, J.: Coupled atmosphere-ocean-wave simulations of a storm event over the Gulf of Lion and Balearic Sea, J. Geophys. Res.-Oceans, 117, C09019, https://doi.org/10.1029/2012JC007924, 2012.

Roullet, G. and Madec, G.: Salt conservation, free surface, and varying levels: a new formulation for ocean general circulation models, J. Geophys. Res.-Oceans, 105, 23927-23942, 2000.

Sanford, T. B., Black, P. G., Haustein, J. R., Feeney, J. W., Forristall, G. Z., and Price, J. F.: Ocean response to a hurricane. Part I: Observations, J. Phys. Oceanogr., 17, 2065-2083, 1987.

Schade, L. R. and Emanuel, K. A.: The ocean's effect on the intensity of tropical cyclones: Results from a simple coupled atmosphere-ocean model, J. Atmos. Sci., 56, 642-651, 1999.

Seity, Y., Brousseau, P., Malardel, S., Hello, G., Bénard, P., Bouttier, F., Lac, C., and Masson, V.: The AROME-France convectivescale operational model, Mon. Weather Rev., 139, 976-991, 2011.
Shay, L. K.: Air-sea interactions in tropical cyclones, in: Global Perspectives on Tropical Cyclones: From Science to Mitigation, 93131, World Scientific, 93-131, 2010.

Sorgente, R., Olita, A., Oddo, P., Fazioli, L., and Ribotti, A.: Numerical simulation and decomposition of kinetic energy in the Central Mediterranean: insight on mesoscale circulation and energy conversion, Ocean Sci., 7, 503-519, https://doi.org/10.5194/os7-503-2011, 2011.

Steffen, J. and Bourassa, M.: Barrier Layer Development Local to Tropical Cyclones based on Argo Float Observations, J. Phys. Oceanogr., 48, 1951-1968, 2018.

Vialard, J. and Delecluse, P.: An OGCM study for the TOGA decade. Part I: Role of salinity in the physics of the western Pacific fresh pool, J. Phys. Oceanogr., 28, 1071-1088, 1998.

Vincent, E. M., Lengaigne, M., Madec, G., Vialard, J., Samson, G., Jourdain, N. C., Menkes, C. E., and Jullien, S.: Processes setting the characteristics of sea surface cooling induced by tropical cyclones, J. Geophys. Res.-Oceans, 117, C02020, https://doi.org/10.1029/2011JC007396, 2012a.

Vincent, E. M., Lengaigne, M., Vialard, J., Madec, G., Jourdain, N. C., and Masson, S.: Assessing the oceanic control on the amplitude of sea surface cooling induced by tropical cyclones, J. Geophys. Res.-Oceans, 117, C05023, https://doi.org/10.1029/2011JC007705, 2012b.

Voldoire, A., Decharme, B., Pianezze, J., Lebeaupin Brossier, C., Sevault, F., Seyfried, L., Garnier, V., Bielli, S., Valcke, S., Alias, A., Accensi, M., Ardhuin, F., Bouin, M.-N., Ducrocq, V., Faroux, S., Giordani, H., Léger, F., Marsaleix, P., Rainaud, R., Redelsperger, J.-L., Richard, E., and Riette, S.: SURFEX v8.0 interface with OASIS3-MCT to couple atmosphere with hydrology, ocean, waves and sea-ice models, from coastal to global scales, Geosci. Model Dev., 10, 4207-4227, https://doi.org/10.5194/gmd-10-4207-2017, 2017.

Wroe, D. R. and Barnes, G. M.: Inflow layer energetics of Hurricane Bonnie (1998) near landfall, Mon. Weather Rev., 131, 1600-1612, 2003.

Yan, Y., Li, L., and Wang, C.: The effects of oceanic barrier layer on the upper ocean response to tropical cyclones, J. Geophys. Res.-Oceans, 122, 4829-4844, 2017.

Yao, Y., Perrie, W., Zhang, W., and Jiang, J.: Characteristics of atmosphere-ocean interactions along North Atlantic extratropical storm tracks, J. Geophys. Res.-Atmos., 113, D14124, https://doi.org/10.1029/2007JD008854, 2008.

Zhang, J. A., Black, P. G., French, J. R., and Drennan, W. M.: First direct measurements of enthalpy flux in the hurricane boundary layer: The CBLAST results, Geophys. Res. Lett., 35, L14813, https://doi.org/10.1029/2008GL034374, 2008. 